\title{
Estimating the Impact of Low-Income Universal Service Programs*
}

by

\author{
Daniel A. Ackerberg \\ University of Michigan
}

\author{
David R. DeRemer \\ Université Libre de Bruxelles (ECARES)
}

\author{
Michael H. Riordan \\ Columbia University
}

\author{
Gregory L. Rosston \\ Stanford Institute for Economic Policy Research
}

Bradley S. Wimmer

University of Nevada, Las Vegas

CES 13-33

June, 2013

The research program of the Center for Economic Studies (CES) produces a wide range of economic analyses to improve the statistical programs of the U.S. Census Bureau. Many of these analyses take the form of CES research papers. The papers have not undergone the review accorded Census Bureau publications and no endorsement should be inferred. Any opinions and conclusions expressed herein are those of the author(s) and do not necessarily represent the views of the U.S. Census Bureau. All results have been reviewed to ensure that no confidential information is disclosed. Republication in whole or part must be cleared with the authors.

To obtain information about the series, see www.census.gov/ces or contact Fariha Kamal, Editor, Discussion Papers, U.S. Census Bureau, Center for Economic Studies 2K132B, 4600 Silver Hill Road, Washington, DC 20233, CES.Papers.List@census.gov. 


\begin{abstract}
This policy study uses U.S. Census microdata to evaluate how subsidies for universal telephone service vary in their impact across low-income racial groups, gender, age, and home ownership. Our demand specification includes both the subsidized monthly price (Lifeline program) and the subsidized initial connection price (Linkup program) for local telephone service. Our quasimaximum likelihood estimation controls for location differences and instruments for price endogeneity. The microdata allow us to estimate the effects of demographics on both elasticities of telephone penetration and the level of telephone penetration. Based on our preferred estimates, the subsidy programs increased aggregate penetration by $6.1 \%$ for low-income households. Our results suggest that Linkup is more cost-effective than Lifeline and that auto-enroll policies are important, which calls into question a recent FCC (2012) decision to reduce Linkup subsidies in favor of Lifeline. Our study can inform the evaluation of similar universal service policies for Internet access.
\end{abstract}

\footnotetext{
* The authors thank Mitali Das, Gautam Gowrisankaran, Jinyong Hahn, Katherine Ho, and seminar participants at Columbia, Harvard, Melbourne, and MIT for helpful comments, Jisun Baek, Anna Bordon, Adrian Cacuci, Carlos Perez, Ting Wu, Dan Steinert, Steve Loughlin, Jason May, Caroline Sandifer and especially Patrick Sun for excellent research assistance, the staffs of public utility commissions for guidance about the local rates and lowincome programs in their respective states, and Jim Lande and Tracy Waldon for information on data available from the FCC. Riordan thanks Toulouse School of Economics for hospitality and research support during 20122013. Any opinions and conclusions expressed herein are those of the author(s) and do not necessarily represent the views of the U.S. Census Bureau. All results have been reviewed to ensure that no confidential information is disclosed.
} 


\section{Introduction}

Universal service for telephony has at least nominally been a public policy concern for over a century. ${ }^{1}$ Universal service policies for ordinary telephone service were expanded significantly in the wake of the 1996 Telecommunications Act, subsequently were expanded to encompass wireless service, and currently are under consideration for Internet service (e.g. Office of Congresswoman Doris Matsui, 2009; Federal Communications Commission, 2012). Globally, universal service in telecommunications can be important for economic growth (Roller and Waverman, 2001), and expanding service is a priority in development policy (Estache and WrenLewis, 2009). Universal service concerns usually are directed at two different, but somewhat overlapping, groups: rural and low-income households. Our focus is to develop a model of the demand of low-income households and to understand the economic factors affecting their decisions to subscribe to telephone service. Our model uses U.S. Census microdata to evaluate the effectiveness of the Lifeline and Linkup subsidy programs at increasing the telephone penetration of low-income households. Our study develops methodology and employs appropriate data for evaluating the effectiveness of low-income subsidy programs. By measuring the determinants of telephone penetration of low-income households across different demographic groups, the study provides policy makers and the Census Bureau new information pertinent to "universal service" and the "digital divide." ${ }^{2}$ The new framework, and an understanding of its data requirements, is important for evaluating current telephone subsidy programs, and potentially for the gathering debate on Internet access subsidies.

Overall telephone penetration in the U.S. is high - over 94\% in 2000 according to the Federal Communications Commission (FCC) "Penetration Report." This substantial achievement of universal service masks considerable demographic variation. Penetration rates are lower for low-income households - less than $87 \%$ of households with income less than

\footnotetext{
${ }^{1}$ The term "universal service" refers to the extent to which households have access to telecommunications services. Mueller (1997) dates the origin of the phrase to the AT\&T's Annual Report in 1907, although this was in reference to AT\&T interconnecting with competitors.

${ }^{2}$ Maintaining and enhancing universal service is a stated goal of the 1996 Telecommunications Act. See Riordan (2002) for a more complete background on the economics of universal service. "Digital divide" refers to differences in the extent to which households have access to advanced telecommunications and information services. There is fair consensus that some kind of digital divide exists, but continuing debate on the causes and magnitude of the divide, and whether it is growing or narrowing, and what, if anything, to do from a policy perspective.

${ }^{3}$ The penetration data for the report (Belinfante, 2001) is based on the Current Population Survey. The report's income cutoffs are in March 1984 dollars, based on the Consumer Price Index for All Urban Consumers (CPI-U) from the Bureau of Labor Statistics (BLS).
} 
$\$ 10,000$ had a working telephone in their households. Telephone penetration in 2000 varied from $80 \%$ for households with an annual income below $\$ 5,000$ to $98.4 \%$ for households above $\$ 75,000$, and from $95.2 \%$ for white households to $89.3 \%$ for black households. The demographic variation was even greater for low-income households. For example, $83.1 \%$ of white households with an annual income below $\$ 5,000$ had telephone service, while $73 \%$ of low-income black households had telephone service. A major goal of our analysis is to better understand the reasons for this demographic variation.

In the United States there are two major low-income support programs for telephone service. The Lifeline program provides a subsidy that reduces monthly charges for eligible lowincome subscribers. The Linkup program reduces the initial connection fee that low-income households pay to establish telephone service. In the wake of the 1996 Telecommunications Act, the FCC dramatically increased the size of its basic Lifeline subsidy and provided additional matching support for state-funded Lifeline programs. ${ }^{4}$ The states responded to the federal matching support opportunity in various ways. The FCC's implementation of the 1996 Act did not change the federal Linkup subsidy. ${ }^{5}$ Figure 1 summarizes the evolution of total federal lowcome support. It shows a sharp jump in support in 1998 that more or less stabilizes around the time of the 2000 Census. After that, the steady growth in payments until 2005 reflects growing support payments for mobile service, and the second jump beginning in 2009 reflects sharply increased payments for prepaid mobile service. Figure 2 illustrates the heterogeneity of penetration rates and low-income support payments across the states. The upper panels show the state-level increases between 1990 and 2000 in penetration rates for households below the poverty line The bottom panels show the corresponding increases in federal low-income support payments (in 2000 dollars) divided by the number of poor households in the state.

Our study differs from prior evaluations of universal service subsidies by taking advantage of confidential microdata from the Long-Form Questionnaire of the 2000 Decennial Census. With demographic details from a cross-section of over a million households, we can estimate how demographics affect both elasticities of telephone adoption and levels of telephone

\footnotetext{
${ }^{4}$ For specifics of the Lifeline program, see the unpublished predecessor of this paper, Ackerberg et al. (2009).

${ }^{5}$ The federal Linkup program reduces low-income subscribers' initial connection charge by 50 percent of the customary charge, or $\$ 30$, whichever is less. Both Lifeline and Linkup are funded by taxes on telecommunications services. To the extent that low-income households are heavy users of the services taxed (e.g. long distance), the overall price reduction is less. Marginal subscribers are not likely to be heavy users of the taxed services, so lowincome telecommunications users presumably experience a price decrease. See Hausman et al. (1993).
} 
penetration, while public data only allow for crude estimates from aggregates at the Census Block Group level. We consider penetration specifically for poor households (rather than overall penetration), so implicitly we allow price sensitivity for low-income populations to differ from the rest of the population. The distinction between the elasticity effects and level effects of demographics is empirically important. We show that home ownership and age do little to explain the differences in the level of penetration between races, but they explain much of the gap in elasticities of adoption between races. We find that young renters are the group that can be most easily influenced through universal service subsidies. Our results matter for public utility commissioners who target particular groups. ${ }^{6}$

Our work further differs in at least three important ways from existing published studies that evaluate the aggregate impact of Lifeline and Linkup. ${ }^{7}$ First, using various data sources, we have constructed a dataset that is more extensive than other datasets used to study low-income telephone penetration. We use prices at a disaggregated level, rather than the state level, and we directly exploit price variation resulting from new Lifeline subsidies introduced in wake of the 1996 Telecommunications Act. We also use specific Linkup prices, rather than a Linkup dummy. ${ }^{8}$ Studies that rely on statewide data use statewide-average residential prices, which mask substantial information because residential service prices can vary substantially within states. ${ }^{9}$ For example, in California in 2000, monthly rates for 100 calls a month for Lifeline customers varied from $\$ 5.01$ to $\$ 6.90$ and for non-Lifeline customers varied from $\$ 11.62$ to $\$ 15.51$. Data on prices and service characteristics obtained from Bell Operating Company (BOC) tariffs and Census microdata on telephone penetration and demographics are matched to more than 6,000 wire centers in 39 states and the District of Columbia. ${ }^{10}$

Second, our preferred specification controls for the possible endogeneity of Lifeline prices. ${ }^{11}$ Lifeline price endogeneity is a concern because states responded to post-1996 changes

\footnotetext{
${ }^{6}$ For example, many state public utility commissions have Lifeline and Linkup programs that target senior citizens.

${ }^{7}$ Unpublished predecessors of this paper, Ackerberg et al. (2009, 2011), also make these advances using public data.

${ }^{8}$ Crandall and Waverman (2000) use a dummy variable for Linkup and obtain an unexpected negative effect on penetration. They suggest the result is a consequence of limited variation: only two states lacked a Linkup program in 1990. They also suggest their Linkup result may be due to reverse-causation: states with high penetration rates choosing not to participate in federal low-income programs.

${ }^{9}$ For example, Garbacz and Thompson $(2002,2003)$ use state-level data from the four decades of the Decennial Census and Erikson, Kaserman, and May (1998) use state-level data from the Current Population Survey.

10 A wire center is a geographic area that includes all customers connected to a particular local switch.

11 Crandall and Waverman (2000) acknowledge the endogeneity issue. They attempted to estimate equations with Lifeline and Linkup as endogenous variables but were unsuccessful.
} 
in federal Lifeline policy differently. Ignoring this endogeneity potentially biases downward the estimated elasticity of demand with respect to Lifeline prices. In addition, we also use the size of the local calling area as an explanatory variable. ${ }^{12}$ The inclusion of this value-of-service variable in the demand specification by itself may alleviate price endogeneity because states typically set higher prices in places with larger local calling areas.

Third, our specifications control for automatic enrollment policies. In some states, there are low-income programs that automatically establish eligibility for Lifeline and Linkup. Households participating in those programs can ask the office administering the program to automatically initiate enrollment. In other states, the burden is on the household to establish eligibility. We interpret automatic enrollment policies as reducing the transaction cost of securing subsidized service.

The rich dataset and our exclusive focus on poor populations allow us to estimate elasticities with respect to Lifeline and Linkup prices. Our estimate of the elasticity of lowincome household demand with respect to actual Lifeline prices is -0.021 , using our preferred model with endogenous prices. Our estimate of the elasticity with respect to actual Linkup prices is -0.014 . Although these estimates are low, they are substantially higher than in recent studies. ${ }^{13}$ For example, Garbacz and Thompson (2003) estimate a price elasticity of demand for local service ranging from -0.006 to -0.011 in 2000 for the population as a whole. ${ }^{14}$ By comparing the two elasticities, we obtain an estimate of these households' discount rate that is equivalent to a $1,723 \%$ annual interest rate, supporting the hypothesis that these households may be severely liquidity constrained. ${ }^{15}$

We determine that Lifeline and Linkup subsidies in 2000 increased the telephone penetration of poor households in our sample by 6.1 percentage points, with a $95 \%$ confidence interval between 2.7 and 9.6 percentage points. We estimate that if states had expanded Lifeline

\footnotetext{
${ }^{12}$ Perl (1984) and Taylor and Kridel (1990) use the size of the local calling area as an explanatory variable.

${ }^{13}$ Earlier studies had estimated higher price elasticities of demand for low-income households than the average income household, thus providing some empirical justification for the first versions of the Lifeline and Linkup programs that were implemented in the 1980s (Perl, 1984; Taylor and Kridel, 1990; Cain and MacDonald, 1991).

${ }^{14}$ Crandall and Waverman (2000) use location-specific local service prices and Lifeline rates in 1990 and find no significant impact of Lifeline programs, and they find the Linkup program has a negative effect on penetration. They do find that a higher charge for connecting a new subscriber leads to an elasticity of penetration ranging from 0.025 to -0.030 with respect to the unsubsidized connection charge. Erikson, Kaserman and Mayo (1998) find that targeted low-income subsidies have a small positive effect on state-level penetration rates, while untargeted subsidies do not have a statistically significant impact on penetration rates.

${ }^{15}$ Adams, Einav, and Levin (2009) estimated a 1,415\% annual discount rate for a subprime loan market, which they interpret similarly.
} 
and Linkup to the a maximum level of funding that fully subsidized Linkup and took full advantage of the federal match for Lifeline, then penetration would have increased by a further 2.1 percentage points, with a $95 \%$ confidence interval between 0.9 and 3.2 percentage points. ${ }^{16}$

We find that Linkup is far more cost effective than Lifeline because it is targeted at lowincome households that do not have telephone service, and because of the extremely large discount rates in this population. We also find that the automatic enrollment programs are effective at increasing telephone penetration. Perhaps surprisingly, the Federal Communications Commission recently eliminated the Linkup support program except on (Native American) Tribal lands (FCC, 2012). We take issue with this reform in our conclusion.

The rest of the paper is organized as follows. The next section lays out a theoretical model of the low-income demand for subsidized telephone service that is the basis for our econometric model, including a justification why low-income demand should depend only on Lifeline and Linkup price and not the normal connection and subscription prices. Section 3 explains our data. Section 4 includes estimation results and policy experiments, and Section 5 concludes.

\section{Model of telephone service subscription}

\section{Basic model}

Telephone service enables a consumer to place and receive calls. The value of service depends on the characteristics of the consumer and on the characteristics of the service. Both sources of variation help explain why different demographic groups have different aggregate penetration rates, as well as why different locations have different penetration rates. Different population groups may exhibit different demands for service due to different tastes, and may be asymmetrically distributed across locations with varying service characteristics (including prices). Our goal is to develop a model that captures these variations.

The following simple model explains how household's probability of subscribing to telephone service depends on the household's group classification and location. Suppose that the population of households can be partitioned into $G$ groups based on observable characteristics,

\footnotetext{
${ }^{16}$ In contrast, Garbacz and Thompson (2003) estimate that a 10 percent increase in Linkup and Lifeline expenditures would have added only 20,000 households to the network in 2000.
} 
and $L$ locations based on service characteristics. The value of service to consumer $i$ belonging to group $g$ at location $l$ is

$$
\gamma_{g}+\left(1+\phi_{g}\right) \delta_{l}+\varepsilon_{i}
$$

where $\gamma_{g}$ and $\phi_{g}$ are group-specific parameters, $\delta_{l}$ is a location fixed effect (that includes, e.g., the effect of location specific prices), and $\varepsilon_{i}$ is an idiosyncratic household characteristic. Assume for simplicity that $\varepsilon_{i}$ has a standard exponential distribution for all groups in all locations. Then $1+\gamma_{g}+\left(1+\phi_{g}\right) \delta_{l}$ is the mean utility of households belonging to group $g$ in location $l$.

The household subscribes to service if the value of service is positive. Therefore, the probability of adoption for a member of group $g$ in location $l$ is:

$$
S_{g l}=\operatorname{Min}\left\{1, \exp \left[\gamma_{g}+\left(1+\phi_{g}\right) \delta_{l}\right]\right\} \equiv S_{g}\left(\delta_{l}\right)
$$

Note the probability of adoption is 1 if the deterministic component of the value of service is weakly greater than 0 . This is because of the positive support of the exponential distribution. Additional structure is placed on the model by assuming that the location fixed effect depends linearly on location characteristics:

$$
\delta_{l}=\theta_{p} p_{l}+\theta_{x} x_{l}+u_{l}
$$

where $p_{l}$ is price of service, $x_{l}$ is a vector of observable exogenous characteristics (including a constant term) and $u_{l}$ is an unobservable characteristic. Finally, the price of service is endogenously determined by exogenous characteristics and another location specific unobservable $v_{l}$ :

$$
p_{l}=\theta_{z} z_{l}+v_{l}
$$

where $z_{l}$ is a vector containing $x_{l}$ and other elements excluded from $x_{l}$. We allow the two location specific unobservables to be correlated. Our particular assumptions about price endogeneity, discussed later, determine the "excluded instruments."

\section{Estimation of the Basic Model}

This basic model of household demand explains variations in observed penetration rates across groups and locations, and provides a basis for estimation. Suppose that location $l$ has $n_{g l}$ households belonging to group $g$. If $\varepsilon_{i}$ is independent across households in a location (and 
independent of the exogenous variables $\left(x_{l}, z_{l},\left\{n_{g l}\right\}_{g=1}^{G}\right)$, then, conditional on $\delta_{l}$, the probability of exactly $m_{g l}$ households adopting service is binomial. Since $\delta_{l}$ is a function of observable data and the unobservables $\left(u_{l}, v_{l}\right)$, we assume $\left(u_{l}, v_{l}\right) \sim N(0, \Sigma)$, also independent of $\left(x_{l}, z_{l},\left\{n_{g l}\right\}_{g=1}^{G}\right)$, and integrate these out to form the likelihood of the endogenous variables $\left(\left\{m_{g l}\right\}_{g=1}^{G}, p_{l}\right)$ at a particular location: ${ }^{17}$

$$
\begin{aligned}
& L\left(\left\{m_{g l}\right\}_{g=1}^{G}, p_{l} \mid x_{l}, z_{l},\left\{n_{g l}\right\}_{g=1}^{G} ; \theta\right) \\
& =L\left(\left\{m_{g l}\right\}_{g=1}^{G} \mid x_{l}, z_{l},\left\{n_{g l}\right\}_{g=1}^{G}, p_{l} ; \theta\right) L\left(p_{l} \mid x_{l}, z_{l},\left\{n_{g l}\right\}_{g=1}^{G} ; \theta\right) \\
& =\left[\int \prod_{g=1}^{G} S_{g l}\left(\delta_{l}\left(u_{l}\right)\right)^{n_{g l}}\left(1-S_{g l}\left(\delta_{l}\left(u_{l}\right)\right)\right)^{m_{g l}-n_{g l}} p_{u \mid v}\left(u_{l} \mid p_{l}-\theta_{z} z_{l}\right) d u_{l}\right] \frac{1}{\sigma_{v}} \phi\left(\frac{p_{l}-\theta_{z} z_{l}}{\sigma_{v}^{2}}\right)
\end{aligned}
$$

where $\phi(\cdot)$ is the standard normal pdf and $p_{u \mid v}\left(u_{l} \mid p_{l}-\theta_{z} z_{l}\right)$ is the conditional normal distribution implied by the variance matrix $\Sigma$. We evaluate the one-dimensional integral in this likelihood using quadrature. ${ }^{18}$

The unobservables $\left(u_{l}, v_{l}\right)$ may capture both unobserved location-specific tastes and unobserved characteristics of telephone service in a particular location. Given the geographic nature of the data, we are hesitant to assume that these unobservables are uncorrelated across locations, particularly those in the same state (since, e.g. unobserved service characteristics might be decided at the state level). One option would be to fully specify the joint distribution of $\left(u_{l}, v_{l}\right)$ across the locations in a state and consider a joint likelihood. Alternatively, we take a semi-parametric approach by following the "quasi-likelihood" literature (Avery, Hansen, and

\footnotetext{
${ }^{17}$ Alternatively, one could treat the $\delta_{l}$ 's as parameters and estimate them (along with the group parameters $\left.\left(\phi_{g}, \gamma_{l}\right)\right)$ based on a simple binomial likelihood. While this provides consistent estimates of $\left(\phi_{g}, \gamma_{l}\right)$ without assumptions on the unobservables $\left(u_{l}, v_{l}\right)$, the parameters $\left(\theta_{p}, \theta_{x}, \theta_{z}\right)$ would need to be estimated in auxiliary regressions (with the estimated $\delta_{l}$ 's as dependent variables, and with assumptions on $\left(u_{l}, v_{l}\right)$ ). Moreover, these auxiliary regressions have complicated censoring problems since not only is $\delta_{l}$ estimated, but it is also not point identified in locations where everyone adopts or nobody adopts.

${ }^{18}$ We simply discretize the conditional normal into a 40 point distribution.
} 
Hotz, 1983; Wooldridge, 2002). More specifically, as long as the marginal distribution of $\left(u_{l}, v_{l}\right)$ in each location $l$ is specified correctly, it will be the case that

$$
E\left[\frac{\partial \ln L\left(\left\{m_{g l}\right\}_{g=1}^{G}, p_{l} \mid x_{l}, z_{l},\left\{n_{g l}\right\}_{g=1}^{G} ; \theta\right)}{\partial \theta}\right]=0 \quad \text { at } \theta=\theta^{0}
$$

This moment can be used to form a GMM estimator for the parameters without specifying the joint distribution of $\left(u_{l}, v_{l}\right)$ across locations. Then, clustering the GMM variance formula at the state level implicitly allows arbitrary dependence across locations. This clustering is particularly important for obtaining realistic standard errors for the price coefficient, since most of the variation in prices (and the instruments for prices) is at the state level.

\section{Allowing for Adoption and Switching Costs}

According to the basic model, the probability that a household belonging to group $g$ at location $l$ has service is $D_{g l}\left(p_{l}\right) \equiv S_{g}\left(\theta_{p} p_{l}+\theta_{x} x_{l}+u_{l}\right)$. If there is an additional time and effort cost for a household to adopt service (or switch to a different type of service), then the constant term in $\theta_{x} x_{l}$ can be interpreted to include this transaction cost, or, more precisely, its amortized value over an appropriate horizon. ${ }^{19}$ Under certain assumptions, this is consistent with a simple dynamic model of service adoption. ${ }^{20}$

Switching costs provide a simple explanation why all eligible households do not adopt lower priced universal plans when these plans unexpectedly become available (our data suggests that this is the case). Suppose that consumers at location $l$ initially pay $p_{l}$ for service, but that a subsidized service plan suddenly becomes available at a discount of $s_{l}$. The expected demand for service increases from $\sum_{g=1}^{G} n_{g l} D_{g l}\left(p_{l}\right)$ to $\sum_{g=1}^{G} n_{g l} D_{g l}\left(p_{l}-s_{l}\right)$. Previous subscribers will continue to pay $p_{l}$ if their cost of switching from normal to subsidized service exceeds $s_{l}$, while new subscribers will pay the discounted price $p_{l}-s_{l}$. The relevant price for determining total demand

\footnotetext{
${ }^{19}$ Similarly, if there is monetary cost of connection or switching, then $p_{l}$ is interpreted to include its amortized value. We will be more explicit about this later in the empirical application of the model.

${ }^{20}$ For example, a situation where price and service characteristics are expected to remain constant over time.
} 
after the introduction of the subsidized plan is $p_{l}-s_{l}$, even though previous subscribers may pay a higher price. That is, the introduction of subsidized service results simply in a movement down the demand curve, and the relevant price for determining total penetration is the subsidized price. $^{21}$

Matters are more complicated if not all households are eligible for the subsidized service plan. If only a fraction $\lambda_{g l}$ of consumers belonging to group $g$ at location $l$ are eligible for the subsidized plan, then the increase in expected subscription is only $\lambda_{g l} n_{g l}\left[D_{g l}\left(p_{l}-s_{l}\right)-D_{g l}\left(p_{l}\right)\right]$. In this case, total penetration would depend on both the normal price $p_{l}$ and the subsidized price $p_{l}-s_{l}$. In this case, estimation of the basic model using only subsidized prices intuitively would yield a downwardly biased estimate of the price elasticity of demand. ${ }^{22}$

\section{Data}

We composed our dataset using various sources: confidential data from the 2000 decennial Census (United States Department of Commerce, 2000), Bell Operating Company (BOC) state telephone tariffs, the FCC, Telcordia (2000) (the Local Exchange Routing Guide, "LERG"), and Claritas (2003). Access to the confidential census data allows us to account for the considerable demographic and geographic variation in telephone penetration. For each wire center, which is our unit of observation, we determined the number of low-income (below the poverty line) households with particular demographic characteristics and whether these household have access to a working telephone. The demographic characteristics we consider are race, home ownership, age, and gender of the head of household. Our main dependent variable is a wire center's penetration rate for low-income households belonging to different demographic groups

\footnotetext{
${ }^{21}$ The same is true if consumers rationally expected the lower price and delay adoption even though they otherwise were willing to adopt at the normal price (assuming they expect the lower price to remain constant into the future), or if there is heterogeneity in switching cost (captured by $\varepsilon_{i}$ ) and the households with lower switching costs do switch plans once the new lower-priced service becomes available.

${ }^{22}$ The elasticity with respect to a subsidy for which all households are eligible is $E=\Delta Q / Q \div S / P$ where $P$ and $Q$ are the initial price and penetration, and $\Delta Q$ is the increase in penetration in response to a small subsidy $S$. If only a fraction $\lambda$ of households were eligible for the subsidy, then the observed change in penetration would be only $\lambda \Delta Q$ and the estimated elasticity would be $\lambda E$. We sought to estimate a fixed $\lambda$ with an alternative more flexible specification that included normal subscription charges as well as Lifeline and Linkup rates. The point estimates across different specifications were close to one, although standard errors were high, and the estimated price sensitivities were similar in magnitude to those we report.
} 
(Penetration); this variable equals the number of low-income households in a particular group with telephone service divided by the total number of low-income households in that demographic group.

Table 1 presents the summary statistics for restricted Census data. The aggregate penetration rate of 91.6 is close to that reported for low-income households in FCC (2010). The 1.01 million household sample includes actual respondents to the Census long-form questionnaire. $^{23}$

The variation in penetration across the major demographics in our study is clear from Table 1. A first glance at the data reveals large variation in the penetration by race in the sample, ranging from 82.8 percent for Native Americans to 97.5 for Asians. The data reveals differences in penetration between renters and owners and seniors and others. There is lesser variation between male and female household heads.

Data on the price of basic local telephone service including connection charges, Lifeline and Linkup discounts, and other information were obtained from the BOC telephone tariffs. Our data set also includes variables that proxy the cost of providing local service and several other variables relevant for state regulation. These variables are used as instruments to control for possible price endogeneity.

Our final dataset for analysis includes 6,426 wire centers from 39 states and the District of Columbia. Our dataset includes states where service was provided by one of the original BOCs where each household in a wire center was charged the same price. ${ }^{24}$ We drop 820 wire centers for which appropriate price data were unavailable, because in rural areas a single switch may serve multiple localities with different prices. Another concern is that takeup of Lifeline and Linkup among eligible households is far less than universal. ${ }^{25}$ Various state eligibility requirements as well as lack of information are potential obstacles to takeup. For eligibility,

\footnotetext{
${ }^{23}$ The sample size differs from the 7.7 million households covered by Ackerberg et al. (2009) because that paper uses the public Census dataset, which weights and aggregates survey responses and imputes the telephone usage of survey non-respondents. There were 12.4 million poor households in the U.S. according to the 2000 Census. ${ }^{24}$ The initial dataset included 7,938 wire centers located in 43 states and the District of Columbia in the original BOC regions. Excluded states are Alaska, Hawaii and Connecticut, which were not served by BOCs; Delaware, which is not included in the FCC (2000a) cost model; and Montana, Wyoming and Vermont, which set different prices for households served by each switch depending on the distance from the switch so that it was impossible to accurately determine the prices faced by low-income households. Southern New England Telephone, which serves Connecticut, was purchased by SBC following passage of the Telecom Act of 1996.

${ }^{25}$ The FCC (2003) estimates that in 2000 only 37.5 percent of the Lifeline-eligible households participated.
} 
some states use income cut-off level, while others use participation in means-tested programs. ${ }^{26}$ Recall that our model addresses the takeup issue by assuming that non-takeup households are not marginal consumers, i.e. these households would have phone service even without the 1996 increase in subsidies. ${ }^{27}$ We drop an additional 692 wire centers in four states where low-income households faced relatively restrictive eligibility criteria.

The explanatory variables of primary interest are the subsidized charge for local service and the subsidized connection charge for initiating service. The empirical analysis uses the variable Lifeline 50, which is the minimum monthly expenditure of Lifeline customers making 50 local calls. ${ }^{28}$ The other price variable of primary interest is Linkup, which is equal to the connection charge paid by customers eligible for the Linkup subsidy.

An important characteristic of telephone service is the number of people within a customer's local calling area (LCA). The independent variable $L C A$ is equal to the number of households within a customer's local calling area. ${ }^{29}$ Customers with flat-rate service can make an unlimited number of calls to customers located within their LCA. When subscribing to a usagebased plan, the rates for local calls are lower than charges for calls outside the customer's LCA. We expect a positive relationship between $L C A$ and Penetration holding other factors constant. We also consider an additional service characteristic variable Autoenroll, which is a dummy variable equal to one if the state has a program that automatically enrolls eligible households for Lifeline and Linkup. The FCC (2003) reports that only three states had automatic

\footnotetext{
${ }^{26}$ For example, households in California whose income falls below $135 \%$ of the poverty level are eligible. Meanstested program include, but are not limited to, Medicaid, Food Stamps Supplement Security Income (SSI), Federal Public Housing Assistance (Section 8), or the Low Income Home Energy Assistance Program.

${ }^{27}$ In Alabama only households receiving Medicaid were eligible for the Lifeline program in 2000; in Colorado households must receive SSI benefits; Maryland requires participation in Temporary Aid to Needy Families; and Virginia requires participation in either Food Stamps or Medicaid. All other states either use an income standard under which all low-income households are eligible, or have less stringent program requirements. Inclusion of the four dropped states in the empirical work does not affect our main estimates.

${ }^{28}$ Customers subscribing to a flat-rate plan pay a monthly charge and are allowed to make an unlimited number of local calls. LifelineX is the minimum basic monthly charge plus usage charges across all available plans assuming the customer completes $\mathrm{X}$ three-minute local calls. The monthly charge component equals the non-Lifeline monthly charge, including the federal subscriber line charge (SLC), less the total Lifeline discount; LifelineX includes extended area of service surcharges when such surcharges are non-optional. See Ackerberg et al. (2011) for a robustness check, in which the estimation uses Lifeline 100, the minimum monthly expense for making 100 calls.

${ }^{29}$ In wire centers that serve more than one locality, the household-weighted average LCA is used for the wire center. $L C A$ is constructed from tariffs, census data, Telecordia (2000), and Claritas (2003).
} 
enrollment programs. ${ }^{30}$ Such programs lower the transaction cost of obtaining subsidized service. $^{31}$

We also control for the median income and population density in a location, thus allowing that telephone service is more (or less) valuable in higher income and less rural/more urban communities. Median Income equals the median income (in \$1000s) of households served by a the wire center, the variable Rural is the percent of wire-center households living in rural areas, and the variable $M S A$ is the percent of wire-center households living in a metropolitan statistical area.

\section{Endogenous Variables and Instruments}

We consider the possible endogeneity of the explanatory variable Lifeline50. As explained earlier, we are particularly concerned about the possible endogeneity of Lifeline rates because the magnitude of the increases in Lifeline subsidies after 1996 varied significantly across states. Endogeneity could arise if state regulators set these subsidies based on $u_{l}$, i.e. unobserved (to the econometrician) service characteristics or characteristics of the low-income population.

In considering the possible endogeneity of Lifeline50, it is useful to suppose that regulators choose an appropriate subsidy for low-income households, and then subtract this from the normal monthly price:

$$
\text { Lifeline } 50_{l}=\text { Monthly50 }- \text { Subsidy } 50_{l}
$$

where Monthly50 is the normal minimum monthly expenditure for 50 calls, and Subsidy50 is the discount offered to Lifeline-eligible low-income households. Since the Subsidy50 component is directed specifically at low-income households, and since these subsidies were significantly

\footnotetext{
${ }^{30}$ The FCC (2003) reports that three states - MA, NY and ND -had automatic enrollment programs. In Massachusetts, households that qualify for the low-income heating assistance program (LIHEAP) were allowed to have the LIHEAP-administrating office contact Verizon and enroll them in the Lifeline program. The New York Department of Family Assistance (NYDFA) automatically enrolled a household in the Lifeline and Linkup program when it enrolled in a NYDFA program. The North Dakota Department of Human Services sent certificates to households that allowed them to enroll in Lifeline and Linkup programs when they were determined eligible for a program that qualified them as eligible for Lifeline and Linkup. Information from Center for Media Education/Center for Policy Alternatives (1999) and local tariffs were used to verify that these programs were in place on January 1, 2000.

${ }^{31}$ Ackerberg et al. (2011) uses public telephone data to consider the effects on penetration of service characteristics not included in the current paper. One experiment involves expanding the Autoenroll dummy to include three states that adopted programs to reduce the transaction costs of enrolling in the Lifeline and Linkup programs. The inclusion of these states does not impact results. Another service characteristic is the rates charged for intrastate long-distance calls, as emphasized by Hausman, Tardiff, and Belinfante (1993). Results using the rate for a fourminute call were the wrong sign and statistically insignificant.
} 
increased in 1996, it seems quite plausible that Subsidy50 $0_{l}$ is correlated with $u_{l}$, the unobserved component of demand for low-income households in 2000. For example, correlation might arise from political pressure for higher Lifeline subsidies in areas with lower low-income penetration rates. On the other hand, the Monthly50 component of Lifeline50 is a price paid by all subscribing households in an area. Presumably, regulators primarily take non-low-income households into account when setting Monthly50, since Subsidy50 can always be adjusted to generate a desired price for low-income households. In addition, Monthly50 prices tend to change fairly slowly over time, so there may be an important historical component to these prices. Hence we believe a priori that it is more likely Subsidy50 is correlated with $u_{l}$ than Monthly50. Our empirical analysis, however, considers both possibilities. ${ }^{32}$

Two other conceivably endogenous variables are Linkup and Autoenroll. Our a priori view is that, even though these variables are also targeted towards low-income households, they are less likely to be endogenous than Lifeline50. The Federal-State Joint Board on Universal Service (FCC 2003) recognizes that implementing automatic enrollment procedures imposes additional administrative burdens and costs, suggesting that this policy decision was determined primarily by infrastructure considerations, i.e. whether state computer systems were up to the task.

Regarding the possible endogeneity of Linkup, an important issue is the way in which the Federal Government funds low-income subsidy programs, and the resulting incentives for states. As discussed in the introduction, the Lifeline and Linkup programs differ in the extent to which the Federal Government provides matching incentives. In the Lifeline program the federal subsidy increases with the amount of state subsidy, i.e. the state subsidy is "matched." In contrast, in the Linkup program the federal subsidy is fixed at $50 \%$ of the customary rate (up to \$30). Thus, any state subsidization of the Linkup rate is not matched by the federal government. Presumably in response to these strong economic incentives, 32 (80\%) of the 40 state (or D.C) governments in our sample provide additional Lifeline subsidies, while only 11 (27.5\%) provide

\footnotetext{
${ }^{32}$ We emphasize that just because Monthly 50 is set for non-low-income households does not guarantee that it is uncorrelated with $u_{l}$ for low-income households. For example, demand shocks may be correlated across low-income and non-low-income households, and Monthly50 might be set in response to non-low-income demand shocks. Or, Monthly50 might be set in response to unobserved product characteristics that affect both non-low-income and lowincome demand.
} 
additional Linkup subsidies. ${ }^{33}$ Summing up, it appears that Linkup is determined for the most part by customary rates and a fixed federal subsidy percentage. ${ }^{34}$ Consequently, it seems plausible that Linkup is exogenous with respect to unobserved state-level variation in lowincome demand conditions. Furthermore, Autoenroll appears to be determined primarily by plausibly exogenous technological constraints. Therefore, we are less concerned with the possible endogeneity of Linkup and/or Autoenroll than with Lifeline50. Ackerberg, et. al. (2011) using public data found no statistical evidence that Linkup and/or Autoenroll are endogenous. ${ }^{35}$

When allowing for the possible endogeneity of Lifeline 50, we need valid instruments for identification. The instruments must be variables that exogenously shift the relevant endogenous variable, but do not directly shift low-income demand and are uncorrelated with demand residuals. ${ }^{36}$ More intuitively, we want "cost-shifters" that affect the subsidized rates but are unrelated to low-income demand. Our primary instruments are State Rural, Competition, Elect $P U C$, and Democrat PUC. State Rural is the percent of rural households in the state (whereas Rural discussed above pertains the percentage of rural households in the wire center). State Rural is interpreted as a proxy for the telephone company's average cost of service in the state because the average cost of service generally decreases with population density. ${ }^{37}$ Higher statewide cost is expected to increase prices because state regulators are required to set rates that recover carriers' overall costs of service in the state. ${ }^{38}$

\footnotetext{
${ }^{33}$ There may be political reasons why states primarily subsidized Lifeline. While Linkup subsidies target a small group of eligible households who have not adopted yet or have just moved, Lifeline subsidies benefit all low-income households. Hence Lifeline subsidies may be politically more feasible.

${ }^{34}$ Like Monthly50, the customary connection charge is set for all households, not specifically for low-income households. Also like Monthly50, this customary rate typically does not vary much over time.

${ }^{35}$ Ackerberg et. al. (2011) acknowledge that not finding endogeneity could be due to the weakness of the instruments for Linkup and/or Autoenroll Regardless, the Lifeline50 coefficients were stable across all possible endogeneity assumptions.

${ }^{36}$ In particular, we maintain that the instruments are uncorrelated with unobserved service characteristics. While this may be a strong assumption, it is very common in the differentiated products demand literature (e.g. Berry, Levinsohn, and Pakes, 1995).

${ }^{37}$ Like Rosston, Savage and Wimmer (2008), we also considered the BOCs' average forward-looking cost of service constructed from the FCC (2000a) Hybrid Cost Proxy Model (HCPM) as an alternative proxy, but discovered that State Rural had more explanatory power. State regulation of rates is generally based on historical rather than forward-looking cost.

${ }^{38}$ Recall that we include the percent of households living in rural areas in the wire center as an explanatory variable (Rural). Hence, we do allow the level of ruralness in a location to affect telephone demand in that location. The instrument State Rural capitalizes on the fact that subsidies are primarily set at the state level. This generates across-state variation in the subsidy conditional on the level of ruralness in a location. We also considered the state poverty rate as an instrument, but found that it did not change our estimates very much.
} 
The variable Competition (FCC, 1996) measures whether a state had allowed competitive entry in 1995, before passage of the Act, and whether competitors had begun providing local switched services in a state by 1995. Knittel (2004) finds that the introduction of competition before the Act reduced the amount of cross-subsidization present in local telephone markets. Specifically, he shows that residential prices were higher and business prices were lower in states with active competition. Our hypothesis is that universal service subsidies might be less generous with less cross-subsidization from the business segment.

Democrat PUC and Elect PUC describe the state public utility commissions and come from NARUC (2000). These commissions played a major role in the determination of their state's Lifeline and Linkup subsidies. Democrat PUC equals the percentage of state public utility commissioners affiliated with the Democratic party, and Elect $P U C$ is a dummy variable indicating if commissioners are elected rather than appointed. Democrats might be more inclined to provide larger subsidies for the poor and elected officials may be more sensitive to the contributions of regulated utilities and set higher residential rates (Rosston, Savage and Wimmer, 2008).

Finally, recalling our decomposition of Lifeline 50, Monthly50 is an additional potential instrument in specifications for which only Subsidy50 is endogenous. Intuitively, using Monthly50 as an instrument exploits the part of the variation in Lifeline50 that is not directed at low-income households as exogenous variation. This should be a particularly strong instrument, since Monthly50 is mechanically related to Lifeline50. In cases where we use Monthly50 as an additional instrument, we drop the instrument State Rural because our arguments above hypothesize that State Rural affects prices primarily through the normal rate. Therefore, if we use Monthly50 as an instrument, State Rural is theoretically redundant.

Table 2 provides summary statistics for the full sample of 6,426 wire centers. The average wire center contains 1,193 poor households. The telephone penetration rate at the wire center level ranges from 0.59 to 1 , with an average of 0.92 . In terms of prices, households eligible for the Lifeline and Linkup subsidies pay \$5.28 a month for telephone service and $\$ 12.68$ to initiate service in the average wire center. 


\section{Results}

Table 3 presents our estimates for the penetration equation under alternative specifications. The explanatory variables determine the probability that a poor household adopts telephone service given the household's demographic characteristics and the Lifeline and Linkup prices and other characteristics of the household's location.

In interpreting the estimates, recall that the value of telephone service of a household belonging to group $g$ depends on the taste parameters $\gamma_{g}$ and $\varphi_{g}$. The parameter $\gamma_{g}$ shifts the mean value of service, while $\left(1+\varphi_{g}\right)$ interacts with location characteristics, including price. Given the exponential nature of the model, $\gamma_{g}$ does not affect a group's price elasticity, so loosely speaking, the $\gamma_{g}$ 's can be interpreted as measuring different levels of demand across demographic groups, while the $\varphi_{g}$ 's can be interpreted as measuring different price responsiveness across groups. This also reflects the intuition behind how the data can separately identify the $\gamma_{g}$ 's from the $\varphi_{g}$ 's - the $\gamma_{g}$ 's are identified from across group differences in the level of penetration rates, and the $\varphi_{g}$ 's are identified from differences in how the groups respond to different prices. We consider forty different demographic groups: five races (White, Black, Asian, Native, Other), and within each race, eight subgroups distinguished by housing status (Renter, Owner), gender (Male, Female), and age (Under 65, Over 65).

Location characteristics include the monthly service price (Lifeline50) and the connection charge (Linkup), the log of the size of the local calling area $(\ln L C A)$, and whether eligible households are enrolled automatically in low-income programs (Autoenroll). Additional location characteristics determining the penetration are the median household income of the wire center (Median Income), the percent households in the wire center classified as living in rural census areas (Rural), and whether the wire center is in an urban area (MSA).

The first column reports the estimates, and standard errors in parentheses, for a particularly simple model for which there are just five groups distinguished by race alone, the $\varphi_{g}$ 's are assumed constant across groups, and all explanatory variables are assumed exogenous. The coefficients on the dummy variables for race (determining $\gamma_{g}$ ) indicate that, ceteris paribus, Asian households have a higher demand for telephone service than White households, while Black, Native American, and other households have a lower demand. The main coefficients of 
interest are those on prices, Lifeline50 and Linkup; these are negative, as expected, and quantitatively small, but significantly different from zero. It is also noteworthy that penetration increases significantly with the size of the local calling area $(\ln L C A)$ and with automatic enrollment (Autoenroll). The remaining location characteristics (Median Income, Rural, MSA) control for how value of service varies with the characteristics of the community served by the wire center.

Another estimate of interest is Discount Rate, which is the ratio of the coefficient on Linkup to the coefficient on Lifeline50. Since Linkup is an initial expense while Lifeline50 is a recurrent monthly expense, Discount Rate converts the initial expense to a monthly one. While the high standard error indicates that Discount Rate is not estimated very precisely, the entire $95 \%$ confidence interval is in a range of quite high monthly discount rates. This may be indicative of our poor households having significant credit constraints as we discuss further later in this section.

The five group model estimated in the first column is the same as in Ackerberg et al. (2011), which relies on public census data. The public data are more aggregated than the confidential census data used in the present paper. Nevertheless, the estimates are roughly the same. The main difference is that the less aggregated data result in lower standard errors, especially on the coefficients related to the demographic variables. The microdata estimates allow us to conclude much more confidently that these estimated coefficients are significantly different from zero.

A further advantage is that the more disaggregated data enables us to control for additional demographic characteristics. The second column of Table 3 reports coefficient estimates for a richer model with forty demographic groups, while still holding the taste parameter $\varphi_{g}$ constant across groups, and maintaining the exogeneity assumption. While the additional demographic characteristics are important for determining demand, the other coefficient estimates do not change very much. The price sensitivity coefficient on Lifeline 50 is lower, suggesting that additional demographic controls correct an omitted variable bias in estimating this key coefficient. The estimated coefficient on Linkup, on the other hand, is stable. As a result, the implied Discount Rate is higher.

The third column reports estimates for the full exogenous model, in which $\varphi_{g}$ and $\gamma_{g}$ both vary across the forty demographic groups. The estimated coefficients on Lifeline50 and 
Linkup are about twice the size of the simpler model, while the corresponding standard errors are much larger. This more flexible model also allows for demographic variation in how demand varies with price and service characteristics. For example, White households are less sensitive to price than Black and Native American households, and are more sensitive than Asian households. These estimates suggest that the more flexible specification yields improved estimates of demand elasticities for different demographic groups.

The remaining specifications allow the Lifeline prices to be endogenous. The fourth column allows the Lifeline subsidy to be endogenous, while maintaining that the normal monthly subscription price is exogenous. The most important effect of this relaxation of the exogeneity assumption is to raise the estimated coefficient on Lifeline50. This suggests that a failure to control for endogeneity biases downward the estimated effect of Lifeline subsidies on the demand for telephone service by poor households. Finally, the fifth column allows the entirety of the Lifeline price to be endogenous. This results in an even greater estimated price sensitivity for Lifeline 50. These results are consistent with Lifeline prices being positively correlated with unobserved components of demand, which seems a plausible result of policies intended to subsidize adoption rates (e.g. where larger subsidies are given in areas with lower demand). The other coefficient estimates of the model are relatively stable across the three different endogeneity hypotheses represented in the last three columns.

In our specification that allows the full Lifeline price to be endogenous, our point estimate of the monthly discount rate is lower than the other specifications (27\%) and arguably more plausible. However, this is still extremely high. Interestingly, Adams, Einav, and Levin (2009) obtain a similar estimate of the discount rate (an annual discount rate of $1,415 \%$, corresponding to about $25 \%$ per month) in their study of subprime auto lending. Our comparison of Linkup and Lifeline elasticities is analogous to their comparison of consumer price responsiveness to loan down payments vs. monthly payments. Presumably our sample of poor households is similar to their sample of purchasers of subprime auto loans, and like them we interpret this as reduced form evidence of severe credit constraints whereby poor households have trouble financing upfront connection charges. ${ }^{39}$ The differential sensitivity to Lifeline and

\footnotetext{
${ }^{39}$ Ideally one might want a formal model of credit constraints, but like Adams, Einav, and Levin (2009), we lack data (e.g. household wealth) to estimate such a model.
} 
Linkup prices that is reflected by our large estimated discount rate plays an important role in the policy analysis later in the paper.

Table 4 reports corresponding estimates for the price equation. The price equation is estimated jointly with the penetration equation to control for possible endogeneity that might bias our estimates (since we do not focus on the price equation itself, we do not estimate a price equation for the exogenous cases). However, when only the amount of Lifeline subsidy is allowed to be endogenous (column IV), both normal levels of monthly prices (Normal50) and whether the state introduced competition early on (Competition95) have important explanatory power for the Lifeline price. In the less restrictive model, in which normal monthly prices also might be endogenous (column V), both competition and whether the state PUC is elected (Elect) are quantitatively and statistically significant independent variables. The result that Lifeline 50 is increasing in both Competition95 and Elect is consistent with our priors that competition limits the regulators' ability to use cross subsidies to lower residential prices and that elected officials may be more sensitive to the contributions of regulated utilities.

Table 4 includes variance and correlation estimates of the error terms for the two equations. These errors are assumed jointly normally distributed. The estimated correlation coefficient can be interpreted as providing a test of the exogeneity hypothesis. Since the estimated correlation is not significantly different from zero in either case, we do not reject the null hypothesis that Lifeline 50 is exogenous. This of course does not rule out possible endogeneity, and we adopt the Lifeline 50 endogenous model in column $\mathrm{V}$ of Table 3 as our preferred specification, because this is less restrictive than the others.

\section{Elasticities}

We adopt the Lifeline Endogenous model as our preferred model and use it to calculate price elasticities for monthly Lifeline charges and initial Linkup charges. These elasticities are calculated by using the model to estimate the percentage aggregate change in penetration for each of the forty demographic groups from raising prices across locations by one percent, as well in the aggregate change for each of the five racial groups. The model is well suited for these calculations because the flexible specification allows price sensitivities to vary with demographic characteristics. 
Our elasticity calculations are based on a counterfactual exercise: How would the penetration levels of different demographic groups change if prices were raised by one percent? To perform the counterfactual, we employ Bayes' Rule and information on actual penetrations at current prices to derive the posterior distribution of the unobservable location characteristics that matter for adoption of telephone service. ${ }^{40}$

The resulting elasticity estimates are reported in Table 5, separately for Lifeline and Linkup. It is apparent that all of the estimated elasticities are small quantitatively. Most, but not all, are statistically significant at conventional levels, although significance levels and standard errors are not reported in the table to avoid clutter. The total elasticities for Lifeline and Linkup are -0.02109 and -0.01404 respectively, and these are significantly different from zero at the 99\% level of confidence. As noted in the Introduction, these estimates are somewhat higher than those previously reported for the general population, and thus consistent with previous findings that the demand of low-income demand households is more price-sensitive. The estimated elasticities are not too different across races, although Blacks and Native Americans have somewhat higher estimated elasticities than other population groups. Homeowner and senior head-of-household subpopulations are less price sensitive than the total low-income population. Part of the reason for the greater overall elasticities of black and Native American low-income populations is be that greater proportions of these are renters, especially for non-senior heads of household.

\section{$\underline{\text { Decompositions }}$}

The summary statistics in Table 1 show relatively large differences in penetration rates across racial groups. It is interesting to use our penetration model to examine the sources of these different penetration rates. In our model there are three possible sources of these differences. First are different tastes for telephone service across the racial groups - these are captured by the race-specific gamma $\left(\gamma_{g}\right)$ and phi $\left(\phi_{g}\right)$ parameters we have estimated. ${ }^{41}$ Second is the possibility that the distribution of racial groups varies across locations. To the extent that a particular racial group lives disproportionately in locations with either lower prices or better service characteristics, that racial group will tend to have higher adoption rates. Third, particular

\footnotetext{
${ }^{40}$ An alternative would be to assume that the unobservable location characteristics were at their mean, i.e. 0.

${ }^{41}$ These taste parameters should be interpreted with care as they could be picking up unmeasured demographic variables that vary across races.
} 
racial groups may have different distributions of the other demographic variables in our model, i.e. owners vs. renters, female vs. male, or senior vs. non-senior. Since our model implies that these other demographics affect adoption decisions, this could also generate differences in aggregate adoption rates of racial groups.

To examine this, we use our model to perform an Oaxaca-Blinder style decomposition (Blinder, 1973; Oaxaca, 1973). Specifically, we take each racial group (as well as the entire population) and either change the taste parameters to those of other groups, change the distribution of locations to those of other racial groups, or change the distribution of demographic characteristics to those of other racial groups. Table 6 reports this decomposition with the taste parameters. The rows indicate the racial group whose parameters will be changed, and the columns indicate the taste parameters that they inherit. The table reports the model's predicted penetration, conditional on the counterfactual taste parameters, other parameters, demographic characteristics, and observed location characteristics. The diagonal of the table (ignoring the "All" row) is the model's predicted penetration rate of each demographic group given actual taste parameters. Looking across a given row gives a sense of the joint impact of the different gamma and phi parameters on a stable population. Of interest is that other than for Native Americans, the different taste parameters do not generate very large differences in adoption rates. For example, the Asian taste parameters only generate adoption rates about 0.5 percentage points higher than the White taste parameters. This suggests the 1.7 percentage point difference between the predicted penetrations of Asians and Whites is driven by observed location characteristics and demographics, rather than different taste parameters.

Table 7 considers hypothetically changing locations of the different racial groups. For example, the cell corresponding to the "White" row and "Asian" column assesses the penetration rate of Whites if they inherited the Asian distribution across locations. ${ }^{42}$ The diagonal of Table 7 is the model's predicted penetration for each group, as in Table 6. The difference between penetration with Asian locations and White locations is 2.5 percentage points, larger than the 1.7 difference between the groups when they are assigned their actual locations. The decomposition suggests that Asians tend to live in locations that have significantly better service attributes than other racial groups, i.e. either lower subsidized prices or better observed or unobserved service

\footnotetext{
${ }^{42}$ In doing this, we keep the distribution of (in this case) White demographics constant within each location. There are alternative ways of doing these decompositions. See Elder, Goddeeris, and Haider (2012) and the literature cited there.
} 
characteristics. Also, when Whites inherit the locations of Native Americans, adoption rates only decrease by 1.6 percentage points. In combination with Table 6 , this result suggests that the more than 10 percentage point difference between actual adoption rates of these two groups is primarily driven by the taste parameters.

Table 8 shows the last decomposition, where each racial group inherits the distribution of demographic characteristics of each other racial group. ${ }^{43}$ While Whites appear to have demographic characteristics most conducive to adoption, the differences across rows are generally smaller than the other tables, suggesting that differences in demographic characteristics are less important in driving overall adoption across racial groups than differences in tastes and locations. The Asian penetration is higher than the White penetration in spite of Whites having the demographics most conducive to adoption. Demographic differences do explain more of the difference between Black and White penetration than location differences, but the taste parameters capture most of the difference in penetration.

To conclude, the most striking conclusions from these decompositions are that the very low adoption rates of Native Americans are primarily driven by taste differences, while the very high adoption rates of Asians are primarily driven by the characteristics of locations where Asians live. The difference in penetration rates of Black and White populations appears to be primarily due to taste differences

\section{Policy Experiment}

We can use the estimates from the variable $\varphi$ - 40 group model in Table 3 to evaluate the impact of the Lifeline and Linkup plans on low-income penetration. ${ }^{44}$ The actual penetration rate for low-income households in our sample is $92.1 \%$. Tables 9 and 10 present the Lifeline Endogenous specifications for Lifeline and Linkup together and then separate the impact of each program. In Table 9, we show the counterfactual penetration rates for the different demographic groups if either or both programs had never existed, and Table 10 conducts a counterfactual exercise in which the programs are expanded together and individually to the maximum levels in areas where they are not fully funded.

\footnotetext{
${ }^{43}$ Again to preserve the joint distribution of location and demographics (within each inheriting group), we keep the distribution of locations constant within each demographic group.

${ }^{44}$ In these policy experiments we assume that normal unsubsidized rates remain unchanged. This is reasonable since 1) low income households are a small component of overall telephone demand, and 2) normal rates are subject to considerable amounts of regulation.
} 
The first column of Table 9 shows the counterfactual penetration with neither Lifeline nor Linkup. The column shows the change in penetration for each group (with the standard deviation and $95 \%$ confidence interval on the subsequent rows). For example, in the Lifeline Endogenous specification, the overall low-income penetration would drop 6.06 percentage points with a 95 percent confidence interval of a drop between 2.72 and 9.58 percentage points. ${ }^{45}$ The second column shows the effect of no Lifeline program while maintaining the Linkup program, and the final column shows the effect of no Linkup while maintaining Lifeline. Since we cannot divide the effect of automatic enrollment policies between the two programs, we attribute the full effect of Autoenroll to the remaining program in each of the two counterfactuals. ${ }^{46}$

Consequently, the effects of changing each program separately do not sum to the effect of changing both program. ${ }^{47}$

Table 10 has a similar structure, but estimates the impact of expanding the programs in areas where they are not at the maximum level. This exercise increases the Lifeline subsidy up to $\$ 10.50$ where it is below that level (unless additional subsidies would lead to a negative monthly price) and increases the Linkup subsidy so that low-income households pay no hookup charges. Expanding both programs in the Lifeline Endogenous case would increase overall penetration by 2.06 percentage points (with a $95 \%$ confidence interval between 0.88 and 3.23 percentage points). ${ }^{48}$

The results in Table 9 and Table 10 indicate that subsidy programs increase penetration more dramatically among low-income renter households than in those that own a home. They also have a much larger impact on younger households. There are slight differences in the impacts across racial groups, but these are much smaller.

\footnotetext{
${ }^{45}$ Standard errors are calculated using bootstrapping. We use a Cholesky decomposition to simulate new coefficients. We assume that the Lifeline and Linkup coefficients are lognormal because positive coefficients would lead to perverse welfare implications.

${ }^{46}$ The full effect of Autoenroll on penetration is approximately 0.4 percentage points. Alternatively, we could have attributed only part of this Autoenroll effect to the remaining program in each counterfactual.

${ }^{47}$ The nonlinear dependence of penetration on prices also contributes to the individual program effects not adding up to the total effect. Nonlinearity explains less than 0.1 percentage points of the difference, since the linear approximation of log penetration is sufficiently accurate in these counterfactuals.

${ }^{48}$ These predictions ignore possibly offsetting factors (Hausman, Tardiff, and Belinfante, 1993). Federal lowincome subsidy programs are funded by taxes on interstate revenues. To the extent that such extra charges are also borne by low-income households, their bills would decrease somewhat, partially offsetting the increase in hookup and monthly charges.
} 


\section{Consumer Welfare}

We can conduct a welfare analysis of the 6.06 percent of our sample who adopt service due to Lifeline and Linkup in our preferred specification. We evaluate welfare in present value terms and find that, within our model, the average consumer receives a surplus of $\$ 37$ from adopting service at the subsidized price. The average adopter receives a one-time linkup subsidy of $\$ 32$ and monthly lifeline subsidy of $\$ 9$, which the consumer values at $\$ 34$ in present dollars using the monthly discount rate of $27 \%$ from our preferred specification. The total present value of the two subsidies is then $\$ 66$. However, we estimate that the present value of the base prices exceeds the consumers' value of service by an average of $\$ 29$, so the average consumer is left with a surplus of $\$ 37$.

\section{$\underline{\text { Costs }}$}

While the cost for an average incremental subscriber is $\$ 66$ for a consumer surplus of $\$ 37$, this calculation does not take into account the full costs of the two programs, because there are enrolled households who would have adopted service without any subsidy. ${ }^{49}$ Though a full welfare analysis taking into account the social benefits of universal service is beyond the scope of this paper, we can estimate the effectiveness of Lifeline and Linkup relative to their overall costs.

First we estimate the amount of federal and state funding for Lifeline and Linkup in our sample. We calculate that funding was \$27.4 million for Lifeline and \$2.1 million for Linkup for the households in our sample. A description of the methodology is in the Appendix. Federal funding provided approximately three-quarters of the funding with the states adding the rest. The average new subscriber brought in by the two programs costs $\$ 519$ per year. $^{50}$

Our results suggest that Linkup is much more cost effective than Lifeline. Linkup costs less than $8 \%$ of the Lifeline program annually. Even if we attribute the full impact of automatic enrollment policies to the Lifeline program, we still find that Linkup has $72 \%$ of Lifeline's effect

\footnotetext{
${ }^{49}$ We do not conduct cost counterfactuals because we lack suitable data for measuring how changes in subsidies affect take-up by existing subscribers.

${ }^{50}$ Our estimate of the cost per household does not account for eligible households whose income exceeds the poverty level. We estimate that over a quarter of the households eligible for the Lifeline and Linkup programs have incomes above the poverty level. Furthermore, there may be additional costs associated with automatic enrollment polices, as well as other implementation costs.
} 
on predicted penetration. ${ }^{51}$ Our estimates suggest that regulators might get the same effect on penetration with substantially less money by increasing the Linkup program and reducing the Lifeline program. The Universal Service Administrative Company (2012) reports that in 2011 the Federal government spent $\$ 1.6$ billion on Lifeline and only about $\$ 123$ million on Linkup; so there is room to undertake this policy adjustment.

There seem to be at least two reasons why Linkup is more cost effective than Lifeline. First, recall that our estimates suggest that low-income households have very high discount rates. Hence, it will be more cost effective for a policymaker (with a more standard discount rate) to subsidize the one-time Linkup price rather than the recurrent monthly Lifeline price. Another reason Linkup is more cost effective is that by definition it is targeted at poor households who do not have telephone service. We estimate that less than $21 \%$ of Lifeline expenses in our sample go to households who would not otherwise subscribe to service. ${ }^{52}$

Our model and cost estimates reveal a wide variety of cost effectiveness of programs across states. ${ }^{53}$ Figure 3 orders the state programs by their total cost per new subscriber. The cost effectiveness of Linkup relative to Lifeline holds for all 39 states plus DC. Figure 4 shows the changes in penetration across states attributed to each program. A comparison to Figure 3 suggests there is no link between the penetration effects and cost effectiveness. Cost ineffectiveness is not simply a result of particular states chasing after higher penetration and lower-value consumers.

\footnotetext{
${ }^{51}$ When we attribute the full effects of Autoenroll to Lifeline, the effect of dropping Lifeline on penetration is 3.53 percentage points. We attribute the remaining 2.53 percentage points of the 6.06 total effect of the two programs to Linkup, so the Linkup effect is 72 percent (2.53/3.53) of the Lifeline effect. This calculation measures the effect of Linkup from a baseline of zero subsidies, while the effect of Lifeline is measured from a baseline of actual Linkup subsidies. Since the demand curve is steeper at lower prices in our exponential demand curve, this choice of baselines intentionally biases the result against Linkup. If we instead chose baselines that favor Linkup, then the Linkup effect would be 77 percent (2.65/3.41) of the Lifeline effect. If we also attributed the full effect of Autoenroll to Linkup instead of Lifeline, then the Linkup effect (3.08) would be greater than the Lifeline effect (2.98).

${ }^{52}$ We calculate the total Lifeline subsidies going to the $6.06 \%$ of households who adopt due to either program according to our model, and divide this total by the observed Lifeline costs of 27 million we project onto our sample. Calculating the corresponding percentage for Linkup is more difficult because the Linkup subsidy is nonrecurring unless a household stops and then renews service. We cannot infer that the Linkup subsidy of our marginal consumers is reflected in the 1999 cost data.

${ }^{53}$ As in our full sample calculation, Linkup is more cost-effective in all states, even though our method of attributing the new subscribers to each individual program is biased against Linkup. Both Figures 3 and 4 attribute the effect of automatic enrollment policies on subscribers to Lifeline. Both consider the effect of Linkup from a baseline policy of zero subsidies, while the effect of Lifeline is measured from a baseline of actual Linkup subsidies; consequently, the Linkup effect is measured on a flatter region of our exponential demand curve.
} 


\section{Conclusions}

Using price and service data from 6,426 wire centers and demographic data from over a million households, we conclude that low-income subsidy programs have increased low-income telephone penetration by 6.1 percentage points. The conclusion is based on estimated price elasticities of demand with respect to subscription and connection charges for poor households of -0.021 and -0.014 respectively. These estimated elasticities are low but nevertheless somewhat higher than previous estimates for all households. The higher estimates are due substantially to bias corrections that account for the possible endogeneity of Lifeline rates in different locations due to different implementations by state regulators. We find that there are differences in the elasticities of different low-income groups. For racial differences in price sensitivity, we find that taste and demographic differences are important. We find that subsidy programs are most effective at increasing penetration among renters and younger populations.

Even with a relatively low price elasticity of demand, the magnitude of Lifeline and Linkup programs are sufficient to reduce substantially the effective prices faced by low-income households so that telephone penetration increases significantly as a result of these programs. The bottom line is that the Lifeline and Linkup programs connected approximately 61 thousand out of 1 million poor households in our sample at an expense of $\$ 519$ each.

Because of low-income households' high discount rates, the Linkup program has a much higher effect on penetration per dollar spent than the Lifeline program. One possible explanation for this is that low-income households may be credit constrained, and even with the typical $50 \%$ discount, initial hookup charges could be daunting. Furthermore, Linkup subsidies are better targeted at households who do not have telephone service. These findings go against the grain of a recent Federal Communications Commission order to eliminate Linkup in most areas (FCC, 2012). The order reasons that "dollars spent on Linkup in its current form can be more effectively spent to improve and modernize the Lifeline program," because it makes questionable sense "to provide Link Up support to (carriers) with high activation fees" when "many consumers have competitive choices among carriers that do not charge an activation fee and do not draw on Link Up support" (FCC, 2012, pp. 120-121). Additional one-time subsidies for new connections, however, might encourage providers to offer promotional discounts on Lifeline service to new customers, e.g. free service for the first few months, and thus improve the targeting and efficiency of universal service subsidies. 


\section{References}

Ackerberg, D., M. Riordan, G. Rosston, and B. Wimmer (2009), "Low-Income Demand for Local Telephone Service: Effects of Lifeline and Linkup," Stanford Institute for Economic Policy Research, Discussion Paper No. 08-047.

Ackerberg, D., M. Riordan, G. Rosston, and B. Wimmer (2011), "Low-Income Demand for Local Telephone Service: Effects of Lifeline and Linkup," mimeo.

Adams, William, Liran Einav, and Jonathan Levin (2009), "Liquidity Constraints and Imperfect Information in Subprime Lending," American Economic Review, 99(1): 49-84.

Avery, R.B., L.P. Hansen, and V.J. Hotz (1983), "Multi Period Probit Models and Orthogonality Condition Estimation," International Economic Review 24: 21-35.

Belinfante, A. (2001) "Telephone Subscribership in the United States," Federal Communications Commission, Industry Analysis Division.

Berry, S., J. Levinsohn, and A. Pakes (1995), "Automobile Prices in Market Equilibrium," Econometrica, 63(4): 841-890.

Blinder, A. S. (1973), "Wage Discrimination: Reduced Form and Structural Estimates”, Journal of Human Resources 8: 436-455

Cain, P. and J. P. MacDonald (1991), "Telephone Pricing Structures: The Effects of Universal Service," Journal of Regulatory Economics, 3: 293-308.

Center for Media Education/ Center for Policy Alternatives (1999), "Sorry, No Number!" dated October 21, 1999, posted at www.stateaction.com.

Claritas (2003), "Block Group to Wirecenter Cross Reference," electronic file provided by Claritas, Ithaca, NY.

Crandall, R., and L. Waverman (2000), Who Pays for Universal Service? When Telephone Subsidies Become Transparent, Washington, DC: Brookings.

Elder, T. Goddeeris, J. and S. Haider (2012) "Isolating the Role of Individual Covariates in Reweighting Estimation" mimeo, Michigan State University

Erikson, R., Kaserman, D. and J. Mayo (1998), "Targeted and Untargeted Subsidy Schemes: Evidence from Post-Divestiture Efforts to Promote Universal Service," Journal of Law and Economics, 41: 477-502.

Estache A., and L. Wren-Lewis (2009) "Toward a Theory of Regulation for Developing Countries: Following Jean-Jacques Laffont's Lead," Journal of Economic Literature, 47 (3), 729-70.

Federal Communications Commission (1996), “Common Carrier Competition”. (2000a), "Hybrid Cost Proxy Model" available at http://www.fcc.gov/wcb/tapd/hcpm/welcome.html. 
(2003) Federal-State Joint Board on Universal Service, CC Docket No. 96-45, FCC

03J-2, Released April 2, 2003, Adopted March 27, 2003

(2010) “Telephone Penetration by Income by State," Industry Analysis Division.

Released May 2010.

(2012), "Report and Order and Further Notice of Proposed Rulemaiking," WC

Docket No. 11-42, FCC 12-11, Released February 6, 2012, Adopted January 31, 2012.

(2013), “2012 Universal Service Monitoring Report,” CC Docket No. 98-202,

Released March 22, 2013.

Garbacz, C., and H.G. Thompson, Jr. (2002), "Estimating Telephone Demand with State

Decennial Census Data from 1970-1990," Journal of Regulatory Economics 21:317-329.

Garbacz, C., and H.G. Thompson, Jr. (2003), "Estimating Telephone Demand with State Decennial Census Data from 1970-1990: Update with 2000 Data," Journal of Regulatory Economics, 34: 373-378.

Hausman, J., Tardiff, T. and A. Belinfante (1993), "The Effects of the Breakup of AT\&T on Telephone Penetration in the United States," American Economic Review, Papers and Proceedings, 83: 178-84.

Knittel, C.R. (2004), "Regulatory Restructuring and Incumbent Price Dynamics: The Case of Local Telephone Restructuring," The Review of Economics and Statistics, 86, 614-625.

Mueller, M. L. (1997) Universal Service: Competition, Interconnection, and Monopoly in the Making of the American Telephone System, Washington, D.C.: AEI Press.

NARUC (National Association of Regulatory Utility Commissioners) (2000) "Membership Directory," Washington D.C.

Oaxaca, R. (1973) "Male-Female Wage Differentials in Urban Labor Markets", International Economic Review, 14: 693-709

Office of Congresswoman Doris Matsui (September 24, 2009) "Matsui Introduces Legislation to Help Low Income Americans Subscribe to the Internet”. Press Release.

Perl, L. (1984) "Revisions to NERA's Residential Demand for Telephone Service 1983," prepared for The Central Services Organization, Inc. of the Bell Operating Companies, NERA, White Plains, NY April 24, 1984.

Riordan, M., (2002) “Universal Residential Telephone Service,” in Cave, Majumdar, and Vogelsang (eds.) Handbook of Telecommunications Economics, Vol 1, Amsterdam: North Holland.

Roller L.-H., and L. Waverman (2001) ""Telecommunications Infrastructure and Economic Development: A Simultaneous Approach," American Economic Review, 91(4), 909-23.

Rosston, G., S. Savage, and B. Wimmer (2008) “The Effect of Private Interests on Regulated Retail and Wholesale Prices," Journal of Law and Economics, 51 (3).

Taylor, L., and K. Kridel (1990) "Residential Demand for Access to the Telephone Network," in A. deFontenay, M. Shugart, and D. Sibley, eds., Telecommunications Demand Modelling, Amsterdam: North Holland. 
Telcordia (2000) "Local Exchange Routing Guide." New Jersey.

United States Department of Commerce (2000) “Census Bureau, 2000 sf3 Documentation,” U.S. Census Bureau, Economics and Statistics Administration.

Universal Service Administrative Company (2012), "2011 Annual Report."

Wooldridge, J.M. (2002), Econometric Analysis of Cross Section and Panel Data, Cambridge: MIT Press. 


\section{Appendix - Estimating Lifeline and Linkup expense in our sample}

Because the sample of wire centers employed in the study does not cover the whole country, it is necessary to estimate the total cost of the Lifeline and Linkup programs for the areas included in the sample. For two reasons, our data in any particular state do not include all of the households who responded to the Census' telephone availability question: 1) RBOCs do not typically serve the entire state; and 2) we drop wire centers for which we could not identify a unique price.

We employ four main sources of data to estimate the cost of the Lifeline and Linkup programs for our sample; 1) FCC ARMIS database, containing data on the number of Lifeline lines in each study area (each company in each state); 2) FCC "Monitoring Report" information on the federal Lifeline and Link-Up subsidies to each study area in each state; 3) FCC (2003) estimates of the number of households eligible for the Lifeline and Linkup programs in each state in 2000; and 4) the census variable P92 (Poverty Status in 1999 of households by household type) to determine the number of poor households in each wire center and study area.

Because households above the poverty level are eligible to receive Lifeline and Linkup subsidies in several states (e.g., California households with incomes below $150 \%$ of the poverty line are eligible for Lifeline and Linkup subsidies), the actual number of Lifeline subscribers may overestimate the number of households receiving Lifeline and Linkup subsidies in households below the poverty level. To estimate the number of households below the poverty level receiving Lifeline and Linkup subsidies, we compared the FCC's estimate of the number of households eligible for the Lifeline subsidy (Eligible $H H$ ) with the actual number of Lifeline recipients (Lifelines) and the number of households below the poverty level (Pov HH). In study areas where households that were eligible for or receiving the Lifeline subsidies exceeded the number of poor households, we deflated the number of Lifeline lines with the following weight: $w=$ Pov HH $/(\max ($ Eligible HH, Lifelines $))$.

In cases where the number of households below the poverty line in a study area exceeds both the number of eligible households and the number of Lifeline lines, we assume that all households receiving the Lifeline subsidy had incomes below the poverty level (i.e. $w=1$ ). Our estimate of the number of households below the poverty line with Lifeline lines then equals the product of observed Lifeline lines in a study area and $w$. The same methodology is used to determine Linkup dollars spent on households below the poverty line. 
Federal and state per line subsidies for Lifeline are calculated for each state as follows:

Subsidy $50=$ Monthly $50-$ Lifeline 50

$$
\text { Federal50 }=\operatorname{Min}\left[\left(\$ 1.75+\text { SLC }+\frac{\text { Monthly } 50-\text { Lifeline } 50-(S L C+\$ 1.75)}{3}\right), \$ 7\right]
$$

State $50=$ Monthly $50-$ Lifeline $50-$ Federal 50 ,

where $S L C$ equals the federal subscriber line charge. ${ }^{54}$ The total Lifeline subsidy in each wire center (and the amount corresponding to the Federal and State governments) equals the product of the number of Lifeline lines allocated to a wire center and the per-line subsidy. To estimate the total Lifeline subsidy provided to the households in our sample for each state, we calculate the average Lifeline subsidy in the state for areas covered by our sample (the sum of the subsidies across the state's wire centers, divided by the sum of households across the state's wire centers), and multiply by the number of households in our sample for the state.

We allocate federal Linkup dollars to each wire center using the product of the share of state poor households corresponding to each wire center and the annual federal Linkup in the state. federal and state per line connection subsidies are calculated as follow:

SubsidyLU $=$ Hookup - Linkup

FederalLU $=\operatorname{Min}(.50 *$ Hookup, 30)

StateLU $=$ Linkup - FederalLU

We estimate number of Linkup households in our data as the ratio of Federal dollars allocated to our data (from above) to Federal per line subsidy. The Federal and state Linkup subsidies per wire center equal the product of the number of estimated Linkups in each wire center and the per-line subsidies. Using a method analogous to our Lifeline calculations, we use the wirecenter-level results to estimate the total Linkup subsidy provided to the households in our sample for each state.

\footnotetext{
${ }^{54}$ With the exception of the District of Columbia, the federal residential SLC equaled $\$ 3.50$ in all states on January 1, 2000. The SLC equaled \$3.32 in the District of Columbia.
} 
Table 1

Summary Statistics for Census Microdata

\begin{tabular}{|l|r|r|}
\hline \hline \multirow{2}{*}{ All } & \multicolumn{2}{|c|}{$\mathrm{N}=1,005,800$ Households } \\
\cline { 2 - 3 } & Share of Sample (\%) & Penetration (\%) \\
\hline \hline Whites & 100.0 & 91.6 \\
\hline Blacks & 59.3 & 93.2 \\
\hline Asians & 24.5 & 88.0 \\
\hline Native & 3.6 & 97.5 \\
\hline Other & 1.2 & 82.8 \\
\hline Under 65 & 11.4 & 90.3 \\
\hline Over 65 & 79.7 & 90.4 \\
\hline Male & 20.3 & 96.3 \\
\hline Female & 43.2 & 90.2 \\
\hline Renter & 56.8 & 92.7 \\
\hline Owner & 67.0 & 90.0 \\
\hline
\end{tabular}

Table 2

Summary Statistics for Location Data

\begin{tabular}{|l|rrrrr|}
\hline & \multicolumn{5}{|c|}{ Full Sample (6,426 wire centers) } \\
\cline { 2 - 6 } & Mean & Median & St.D. & Min & Max \\
\hline \hline Poor households & 1193 & 419 & 2026 & 3 & 25740 \\
Penetration & .92 & .94 & .06 & .59 & 1 \\
Lifeline50 & 5.28 & 5.50 & 2.43 & 0 & 14.75 \\
Lifeline100 & 7.35 & 7.35 & 3.21 & .55 & 15.32 \\
Linkup & 12.68 & 12.50 & 7.47 & 0 & 22.95 \\
Hookup & 37.00 & 37.07 & 11.29 & 12 & 65.00 \\
Subsidy Linkup & 24.32 & 21.00 & 12.21 & 6 & 55.00 \\
Autoenroll & .12 & .00 & .32 & .00 & 1.00 \\
Access Charge & .15 & .14 & .10 & .03 & .47 \\
LCA & 211671 & 63127 & 407046 & 203 & 3067673 \\
Median Income & 43176 & 38969 & 16992 & 12869 & 175762 \\
Rural & .39 & .21 & .41 & 0 & 1 \\
MSA & .63 & 1.00 & .48 & 0 & 1 \\
State Rural & .25 & .23 & .14 & 0 & .60 \\
Competition & .17 & .00 & .38 & 0 & 1 \\
Elect PUC & .16 & .00 & .37 & 0 & 1 \\
Democrat PUC & 32.85 & 33.33 & 26.09 & 0 & 100 \\
Monthly50 & 13.59 & 13.58 & 2.58 & 8.55 & 21.75 \\
Subsidy50 & 8.31 & 8.25 & 2.14 & 5.25 & 13.65 \\
\hline
\end{tabular}


Table 3

Penetration Equation

\begin{tabular}{|c|c|c|c|c|c|c|c|c|c|c|c|}
\hline \multirow{3}{*}{\multicolumn{2}{|c|}{ geneity }} & \multirow{2}{*}{\multicolumn{2}{|c|}{1}} & \multirow{2}{*}{\multicolumn{2}{|c|}{$\mathrm{II}$}} & \multirow{2}{*}{\multicolumn{2}{|c|}{ III }} & \multirow{2}{*}{\multicolumn{2}{|c|}{ IV }} & \multirow{2}{*}{\multicolumn{2}{|c|}{$\mathrm{V}$}} \\
\hline & & & & & & & & & & & \\
\hline & & \multicolumn{2}{|c|}{ None } & \multicolumn{2}{|c|}{ None } & \multicolumn{2}{|c|}{ None } & \multicolumn{2}{|c|}{ Subsidy50 } & \multicolumn{2}{|c|}{ Lifeline 50} \\
\hline \multirow[t]{7}{*}{$\varphi$} & Black & & & & & $\begin{array}{r}0.1276 \\
(0.0380)\end{array}$ & & $\begin{array}{r}0.1291 \\
(0.0384)\end{array}$ & & $\begin{array}{r}0.1268 \\
(0.0373)\end{array}$ & $* * *$ \\
\hline & Asian & & & & & $\begin{array}{l}-0.0365 \\
(0.0069)\end{array}$ & $* * *$ & $\begin{array}{l}-0.0370 \\
(0.0069)\end{array}$ & $* * *$ & $\begin{array}{l}-0.0360 \\
(0.0067)\end{array}$ & $* * *$ \\
\hline & Native & & & & & $\begin{array}{r}0.2429 \\
(0.1641)\end{array}$ & & $\begin{array}{r}0.2437 \\
(0.1645)\end{array}$ & & $\begin{array}{r}0.2358 \\
(0.1619)\end{array}$ & \\
\hline & Other & & & & & $\begin{array}{r}0.0639 \\
(0.0243)\end{array}$ & $* * *$ & $\begin{array}{r}0.0648 \\
(0.0246)\end{array}$ & $* * *$ & $\begin{array}{r}0.0642 \\
(0.0248)\end{array}$ & $* * *$ \\
\hline & Owner & & & & & $\begin{array}{l}-0.3734 \\
(0.0161)\end{array}$ & $* * *$ & $\begin{array}{l}-0.3729 \\
(0.0155)\end{array}$ & $* * *$ & $\begin{array}{l}-0.3742 \\
(0.0157)\end{array}$ & $* * *$ \\
\hline & Female & & & & & $\begin{array}{l}-0.2315 \\
(0.0177)\end{array}$ & $* * *$ & $\begin{array}{l}-0.2313 \\
(0.0176)\end{array}$ & $* * *$ & $\begin{array}{l}-0.2316 \\
(0.0173)\end{array}$ & $* * *$ \\
\hline & Over 65 & & & & & $\begin{array}{l}-0.3575 \\
(0.0151)\end{array}$ & $* * *$ & $\begin{array}{l}-0.3579 \\
(0.0156)\end{array}$ & $* * *$ & $\begin{array}{l}-0.3571 \\
(0.0154)\end{array}$ & $* * *$ \\
\hline \multirow[t]{7}{*}{$\gamma$} & Black & $\begin{array}{l}-0.0392 \\
(0.0052)\end{array}$ & $* * *$ & $\begin{array}{l}-0.0311 \\
(0.0038)\end{array}$ & $* * *$ & $\begin{array}{l}-0.0121 \\
(0.0034)\end{array}$ & $* * *$ & $\begin{array}{l}-0.0119 \\
(0.0035)\end{array}$ & $* * *$ & $\begin{array}{l}-0.0120 \\
(0.0034)\end{array}$ & $* * *$ \\
\hline & Asian & $\begin{array}{r}0.0113 \\
(0.0009)\end{array}$ & $* * *$ & $\begin{array}{r}0.0198 \\
(0.0020)\end{array}$ & $* * *$ & $\begin{array}{r}0.0030 \\
(0.0008)\end{array}$ & $* * *$ & $\begin{array}{r}0.0029 \\
(0.0008)\end{array}$ & $* * *$ & $\begin{array}{r}0.0031 \\
(0.0008)\end{array}$ & $* * *$ \\
\hline & Native & $\begin{array}{l}-0.0972 \\
(0.0119)\end{array}$ & $* * *$ & $\begin{array}{l}-0.0903 \\
(0.0120)\end{array}$ & $* * *$ & $\begin{array}{l}-0.0614 \\
(0.0132)\end{array}$ & $* * *$ & $\begin{array}{l}-0.0610 \\
(0.0132)\end{array}$ & $* * *$ & $\begin{array}{l}-0.0616 \\
(0.0128)\end{array}$ & $* * *$ \\
\hline & Other & $\begin{array}{l}-0.0309 \\
(0.0068)\end{array}$ & $* * *$ & $\begin{array}{l}-0.0191 \\
(0.0042)\end{array}$ & $* * *$ & $\begin{array}{l}-0.0156 \\
(0.0053)\end{array}$ & $* * *$ & $\begin{array}{l}-0.0155 \\
(0.0052)\end{array}$ & $* * *$ & $\begin{array}{l}-0.0156 \\
(0.0053)\end{array}$ & $* * *$ \\
\hline & Owner & & & $\begin{array}{r}0.0419 \\
(0.0034)\end{array}$ & $* * *$ & $\begin{array}{r}0.0040 \\
(0.0012)\end{array}$ & $* * *$ & $\begin{array}{r}0.0041 \\
(0.0012)\end{array}$ & $* * *$ & $\begin{array}{r}0.0039 \\
(0.0012)\end{array}$ & $* * *$ \\
\hline & Female & & & $\begin{array}{r}0.0232 \\
(0.0033)\end{array}$ & $* * *$ & $\begin{array}{l}-0.0002 \\
(0.0016)\end{array}$ & & $\begin{array}{l}-0.0001 \\
(0.0017)\end{array}$ & & $\begin{array}{l}-0.0002 \\
(0.0015)\end{array}$ & \\
\hline & Over 65 & & & $\begin{array}{r}0.0302 \\
(0.0035)\end{array}$ & $* * *$ & $\begin{array}{l}-0.0077 \\
(0.0010)\end{array}$ & $* * *$ & $\begin{array}{l}-0.0078 \\
(0.0010)\end{array}$ & $* * *$ & $\begin{array}{l}-0.0077 \\
(0.0011)\end{array}$ & $* * *$ \\
\hline \multicolumn{2}{|c|}{ Life50 } & $\begin{array}{l}-0.0020 \\
(0.0004)\end{array}$ & $* * *$ & $\begin{array}{l}-0.0015 \\
(0.0003)\end{array}$ & $* * *$ & $\begin{array}{l}-0.0032 \\
(0.0015)\end{array}$ & $* *$ & $\begin{array}{l}-0.0042 \\
(0.0018)\end{array}$ & $* *$ & $\begin{array}{l}-0.0060 \\
(0.0027)\end{array}$ & $* *$ \\
\hline \multicolumn{2}{|c|}{ Linkup } & $\begin{array}{l}-0.0008 \\
(0.0004)\end{array}$ & $* *$ & $\begin{array}{l}-0.0009 \\
(0.0001)\end{array}$ & $* * *$ & $\begin{array}{l}-0.0016 \\
(0.0007)\end{array}$ & $* *$ & $\begin{array}{l}-0.0016 \\
(0.0006)\end{array}$ & $* *$ & $\begin{array}{l}-0.0017 \\
(0.0006)\end{array}$ & $* *$ \\
\hline \multicolumn{2}{|c|}{$\ln L C A$} & $\begin{array}{r}0.0065 \\
(0.0008)\end{array}$ & $* * *$ & $\begin{array}{r}0.0054 \\
(0.0003)\end{array}$ & $* * *$ & $\begin{array}{r}0.0115 \\
(0.0017)\end{array}$ & $* * *$ & $\begin{array}{r}0.0115 \\
(0.0015)\end{array}$ & $* * *$ & $\begin{array}{r}0.0112 \\
(0.0016)\end{array}$ & $* * *$ \\
\hline \multicolumn{2}{|c|}{ Autoenroll } & $\begin{array}{r}0.0259 \\
(0.0022)\end{array}$ & $* * *$ & $\begin{array}{r}0.0240 \\
(0.0017)\end{array}$ & $* * *$ & $\begin{array}{r}0.0491 \\
(0.0060)\end{array}$ & $* * *$ & $\begin{array}{r}0.0508 \\
(0.0053)\end{array}$ & $* * *$ & $\begin{array}{r}0.0112 \\
(0.0016)\end{array}$ & $* * *$ \\
\hline \multicolumn{2}{|c|}{ Median income } & $\begin{array}{r}1.3389 \\
(0.0890)\end{array}$ & $* * *$ & $\begin{array}{r}1.3829 \\
(0.1156)\end{array}$ & $* * *$ & $\begin{array}{r}2.0641 \\
(0.1527)\end{array}$ & $* * *$ & $\begin{array}{r}2.0268 \\
(0.1706)\end{array}$ & $* * *$ & $\begin{array}{l}2.0826 \\
(0.1775)\end{array}$ & $* * *$ \\
\hline \multicolumn{2}{|c|}{ Rural \% } & $\begin{array}{l}-0.0177 \\
(0.0062)\end{array}$ & $* * *$ & $\begin{array}{l}-0.0220 \\
(0.0060)\end{array}$ & $* * *$ & $\begin{array}{l}-0.0517 \\
(0.0104)\end{array}$ & $* * *$ & $\begin{array}{l}-0.0503 \\
(0.0108)\end{array}$ & $* * *$ & $\begin{array}{l}-0.0496 \\
(0.0115)\end{array}$ & $* * *$ \\
\hline \multicolumn{2}{|c|}{$M S A$} & $\begin{array}{r}0.0085 \\
(0.0043)\end{array}$ & $* *$ & $\begin{array}{r}0.0068 \\
(0.0024)\end{array}$ & $* * *$ & $\begin{array}{r}0.0152 \\
(0.0065)\end{array}$ & $* *$ & $\begin{array}{r}0.0146 \\
(0.0071)\end{array}$ & $* *$ & $\begin{array}{r}0.0146 \\
(0.0074)\end{array}$ & $* *$ \\
\hline \multicolumn{2}{|c|}{ Constant } & $\begin{array}{r}-0.1876 \\
0.0000 \\
\end{array}$ & $* * *$ & $\begin{array}{l}-0.2141 \\
(0.0151) \\
\end{array}$ & $* * *$ & $\begin{array}{l}-0.3057 \\
(0.0335) \\
\end{array}$ & $* * *$ & $\begin{array}{l}-0.3000 \\
(0.0292) \\
\end{array}$ & $* * *$ & $\begin{array}{l}-0.2878 \\
(0.0322) \\
\end{array}$ & $* * *$ \\
\hline \multicolumn{2}{|c|}{ Discount Rate } & $\begin{array}{r}0.4094 \\
(0.1834)\end{array}$ & $* *$ & $\begin{array}{r}0.5525 \\
(0.0762) \\
\end{array}$ & $* * *$ & $\begin{array}{r}0.5046 \\
(0.2274)\end{array}$ & $* *$ & $\begin{array}{r}0.3710 \\
(0.1456)\end{array}$ & $* *$ & $\begin{array}{r}0.2737 \\
(0.1050) \\
\end{array}$ & $* * *$ \\
\hline
\end{tabular}


Table 4

Price Equation

\begin{tabular}{|c|c|c|c|c|c|c|c|}
\hline & 1 & II & III & IV & & $\mathrm{V}$ & \\
\hline Price Endogeneity & None & None & None & Subsidys & & Lifelines & \\
\hline Linkup & \multirow{19}{*}{ N.A. } & \multirow{19}{*}{ N.A. } & \multirow{19}{*}{ N.A. } & $\begin{array}{l}-0.0212 \\
(0.0437)\end{array}$ & & $\begin{array}{l}-0.0219 \\
(0.0437)\end{array}$ & \\
\hline $\ln L C A$ & & & & $\begin{array}{l}-0.0303 \\
(0.0962)\end{array}$ & & $\begin{array}{r}0.0669 \\
(0.0943)\end{array}$ & \\
\hline Autoenroll & & & & $\begin{array}{l}-0.8944 \\
(1.0422)\end{array}$ & & $\begin{array}{r}0.9763 \\
(0.5963)\end{array}$ & \\
\hline Median Income & & & & $\begin{array}{r}0.0422 \\
(4.3640)\end{array}$ & & $\begin{array}{r}5.2449 \\
(5.6530)\end{array}$ & \\
\hline Rural \% & & & & $\begin{array}{l}-0.0405 \\
(0.2041)\end{array}$ & & $\begin{array}{r}0.0456 \\
(0.1805)\end{array}$ & \\
\hline$M S A$ & & & & $\begin{array}{r}0.3170 \\
(0.2063) \\
\end{array}$ & & $\begin{array}{r}0.2517 \\
(0.1888) \\
\end{array}$ & \\
\hline Elect & & & & $\begin{array}{l}1.9871 \\
(1.3955)\end{array}$ & & $\begin{array}{r}3.1851 \\
(1.2441)\end{array}$ & $* *$ \\
\hline$\%$ Dem & & & & $\begin{array}{l}-0.0054 \\
(0.0117)\end{array}$ & & $\begin{array}{l}-0.0034 \\
(0.0113)\end{array}$ & \\
\hline Competition95 & & & & $\begin{array}{r}1.3551 \\
(0.8222)\end{array}$ & $*$ & $\begin{array}{r}2.1808 \\
(0.7885)\end{array}$ & $* * *$ \\
\hline State Rural \% & & & & & & $\begin{array}{r}3.6182 \\
(2.9130)\end{array}$ & \\
\hline Normal50 & & & & $\begin{array}{r}0.4415 \\
(0.1573)\end{array}$ & $* * *$ & & \\
\hline State Blacks & & & & $\begin{array}{l}-2.1948 \\
(2.5403)\end{array}$ & & $\begin{array}{l}-3.1271 \\
(2.4430)\end{array}$ & \\
\hline State Asians & & & & $\begin{array}{r}15.9911 \\
(14.5575)\end{array}$ & & $\begin{array}{r}7.9374 \\
(15.1935)\end{array}$ & \\
\hline State Natives & & & & $\begin{array}{r}11.2501 \\
(11.5173)\end{array}$ & & $\begin{array}{r}12.1133 \\
(11.7632)\end{array}$ & \\
\hline State Others & & & & $\begin{array}{l}-9.7712 \\
(6.4709) \\
\end{array}$ & & $\begin{array}{r}10.6269 \\
(7.7711) \\
\end{array}$ & \\
\hline Constant & & & & $\begin{array}{r}0.0971 \\
(2.2533) \\
\end{array}$ & & $\begin{array}{r}3.7748 \\
(1.8702) \\
\end{array}$ & $* *$ \\
\hline$\sigma \_u$ & & & & $\begin{array}{r}0.0584 \\
(0.0043)\end{array}$ & **** & $\begin{array}{r}0.0591 \\
(0.0043)\end{array}$ & $* * *$ \\
\hline$\sigma \_p$ & & & & $\begin{array}{r}1.6072 \\
(0.1605)\end{array}$ & $* * *$ & $\begin{array}{r}1.7343 \\
(0.2110)\end{array}$ & $* * *$ \\
\hline Correlation & & & & $\begin{array}{r}0.0786 \\
(0.0689)\end{array}$ & & $\begin{array}{r}0.1649 \\
(0.0990)\end{array}$ & * \\
\hline
\end{tabular}


Table 5

Elasticities at Actual Prices

\begin{tabular}{|c|c|c|c|c|c|c|c|}
\hline \multicolumn{8}{|l|}{ Lifeline } \\
\hline & & & White & Black & Asian & Native & Other \\
\hline \multirow[t]{4}{*}{ Male } & \multirow[t]{2}{*}{ Under 65} & Renter & -0.03424 & -0.04146 & -0.02003 & -0.04421 & -0.02825 \\
\hline & & Owner & -0.01931 & -0.02178 & -0.01185 & -0.03197 & -0.01536 \\
\hline & \multirow[t]{2}{*}{ Over 65} & Renter & -0.02184 & -0.02531 & -0.01410 & -0.03637 & -0.02281 \\
\hline & & Owner & -0.00872 & -0.00981 & -0.00462 & -0.01797 & -0.00868 \\
\hline \multirow[t]{4}{*}{ Female } & \multirow[t]{2}{*}{ Under 65} & Renter & -0.02399 & -0.02934 & -0.01569 & -0.03652 & -0.02416 \\
\hline & & Owner & -0.01271 & -0.01420 & -0.01015 & -0.02533 & -0.01238 \\
\hline & \multirow[t]{2}{*}{ Over 65} & Renter & -0.00878 & -0.01251 & -0.01018 & -0.0196 & -0.01273 \\
\hline & & Owner & -0.00154 & -0.00386 & -0.00035 & -0.01073 & -0.00275 \\
\hline All & \multicolumn{2}{|c|}{-0.02109} & -0.01796 & -0.02612 & -0.01620 & -0.03488 & -0.02287 \\
\hline \multicolumn{8}{|l|}{ Linkup } \\
\hline & & & White & Black & Asian & Native & Other \\
\hline \multirow[t]{4}{*}{ Male } & \multirow[t]{2}{*}{ Under 65} & Renter & -0.01452 & -0.02768 & -0.01308 & -0.02665 & -0.01911 \\
\hline & & Owner & -0.01173 & -0.01554 & -0.00745 & -0.01853 & -0.01038 \\
\hline & \multirow[t]{2}{*}{ Over 65} & Renter & -0.01302 & -0.01731 & -0.00997 & -0.02078 & -0.01465 \\
\hline & & Owner & -0.00511 & -0.00745 & -0.00249 & -0.01137 & -0.00621 \\
\hline \multirow[t]{4}{*}{ Female } & \multirow[t]{2}{*}{ Under 65} & Renter & -0.01504 & -0.01915 & -0.01051 & -0.02141 & -0.01602 \\
\hline & & Owner & -0.00802 & -0.01035 & -0.00719 & -0.01454 & -0.00821 \\
\hline & \multirow[t]{2}{*}{ Over 65} & Renter & -0.00623 & -0.00818 & -0.00702 & -0.01248 & -0.00783 \\
\hline & & Owner & -0.00097 & -0.00282 & -0.00023 & -0.00623 & -0.00184 \\
\hline All & \multicolumn{2}{|c|}{-0.01404} & -0.01239 & -0.01741 & -0.01069 & -0.02063 & -0.01531 \\
\hline
\end{tabular}


Table 6

Coefficient Variance Decomposition

\begin{tabular}{|l|l|r|r|r|rr|}
\hline \multicolumn{2}{|c|}{ Variable $\varphi, 40$ group } & White & Black & Asian & Native & Other \\
\hline \hline \multirow{2}{*}{ All } & All & 92.42 & 90.05 & 93.07 & 84.72 & 90.41 \\
\cline { 2 - 7 } & White & 92.56 & 90.16 & 93.22 & 84.80 & 90.53 \\
& Black & 91.94 & 89.48 & 92.61 & 84.08 & 89.87 \\
& Asian & 93.69 & 91.82 & 94.19 & 86.96 & 91.98 \\
& Native & 90.60 & 87.97 & 91.32 & 82.47 & 88.45 \\
& Other & 92.53 & 90.37 & 93.11 & 85.22 & 90.63 \\
\hline Subsidy & All & 92.41 & 90.03 & 93.06 & 84.73 & 90.39 \\
\cline { 2 - 7 } Endogenous & White & 92.54 & 90.13 & 93.20 & 84.80 & 90.50 \\
& Black & 91.92 & 89.46 & 92.59 & 84.08 & 89.85 \\
& Asian & 93.70 & 91.83 & 94.20 & 86.99 & 91.99 \\
& Native & 90.52 & 87.87 & 91.25 & 82.40 & 88.36 \\
& Other & 92.56 & 90.41 & 93.14 & 85.29 & 90.66 \\
\hline Lifeline & All & 92.39 & 90.03 & 93.04 & 84.73 & 90.37 \\
\cline { 2 - 7 } Endogenous & White & 92.54 & 90.15 & 93.20 & 84.83 & 90.50 \\
& Black & 91.86 & 89.40 & 92.53 & 84.02 & 89.77 \\
& Asian & 93.71 & 91.84 & 94.20 & 87.00 & 91.99 \\
& Native & 90.41 & 87.76 & 91.14 & 82.30 & 88.24 \\
& Other & 92.56 & 90.43 & 93.15 & 85.31 & 90.67 \\
\hline
\end{tabular}


Table 7

Location Variance Decomposition

\begin{tabular}{|l|l|r|r|r|rr|}
\hline \multicolumn{2}{|c|}{ Variable $\varphi, 40$ group } & White & Black & Asian & Native & Other \\
\hline \hline \multirow{2}{*}{ Ell } & All & 91.38 & 91.06 & 93.90 & 90.00 & 92.57 \\
\cline { 2 - 7 } & White & 92.56 & 92.26 & 94.88 & 91.28 & 93.63 \\
& Black & 89.82 & 89.49 & 92.62 & 88.33 & 91.20 \\
& Asian & 91.69 & 91.36 & 94.18 & 90.27 & 92.94 \\
& Native & 84.33 & 83.77 & 87.71 & 82.43 & 85.72 \\
& Other & 89.22 & 88.91 & 92.11 & 87.66 & 90.64 \\
\hline Subsidy & All & 91.36 & 91.04 & 93.90 & 89.93 & 92.59 \\
\cline { 2 - 7 } Endogenous & White & 92.54 & 92.24 & 94.88 & 91.22 & 93.65 \\
& Black & 89.80 & 89.46 & 92.63 & 88.25 & 91.23 \\
& Asian & 91.68 & 91.40 & 94.19 & 90.19 & 92.97 \\
& Native & 84.28 & 83.80 & 87.68 & 82.35 & 85.75 \\
& Other & 89.21 & 88.87 & 92.11 & 87.58 & 90.66 \\
\hline Lifeline & All & 91.35 & 90.98 & 93.91 & 89.82 & 92.60 \\
\cline { 2 - 7 } Endogenous & White & 92.53 & 92.18 & 94.88 & 91.12 & 93.65 \\
& Black & 89.81 & 89.40 & 92.65 & 88.15 & 91.25 \\
& Asian & 91.66 & 91.34 & 94.21 & 90.05 & 92.97 \\
& Native & 84.37 & 83.70 & 87.66 & 82.24 & 85.82 \\
& Other & 89.20 & 88.79 & 92.13 & 87.44 & 90.66 \\
\hline
\end{tabular}


Table 8

Demographic Variance Decomposition

\begin{tabular}{|l|l|r|r|r|r|r|}
\hline \multicolumn{2}{|c|}{ Variable $\varphi, 40$ group } & White & Black & Asian & Native & Other \\
\hline \hline \multirow{2}{*}{ All } & All & 91.75 & 91.04 & 90.23 & 90.75 & 90.60 \\
\cline { 2 - 7 } & White & 92.56 & 91.68 & 90.93 & 91.46 & 91.34 \\
& Black & 89.96 & 89.49 & 88.21 & 88.87 & 88.68 \\
& Asian & 94.83 & 94.49 & 94.18 & 94.46 & 94.19 \\
& Native & 83.09 & 82.32 & 81.54 & 82.51 & 82.14 \\
& Other & 91.32 & 90.94 & 90.56 & 90.78 & 90.64 \\
\hline Subsidy & All & 91.74 & 91.02 & 90.21 & 90.73 & 90.58 \\
\cline { 2 - 7 } & White & 92.55 & 91.65 & 90.91 & 91.43 & 91.31 \\
& Black & 89.95 & 89.47 & 88.18 & 88.85 & 88.65 \\
& Asian & 94.84 & 94.51 & 94.18 & 94.47 & 94.19 \\
& Native & 83.02 & 82.24 & 81.46 & 82.37 & 82.05 \\
& Other & 91.36 & 90.97 & 90.58 & 90.82 & 90.66 \\
\hline \multirow{5}{*}{ Eifeline } & All & 91.72 & 91.01 & 90.18 & 90.71 & 90.56 \\
\cline { 2 - 7 } & White & 92.54 & 91.65 & 90.91 & 91.43 & 91.31 \\
& Black & 89.88 & 89.40 & 88.10 & 88.79 & 88.58 \\
& Asian & 94.84 & 94.52 & 94.19 & 94.48 & 94.20 \\
& Native & 82.92 & 82.15 & 81.37 & 82.32 & 81.95 \\
& Other & 91.35 & 90.96 & 90.57 & 90.80 & 90.66 \\
\hline
\end{tabular}


Table 9

Estimated Impact of Subsidy Elimination on Penetration

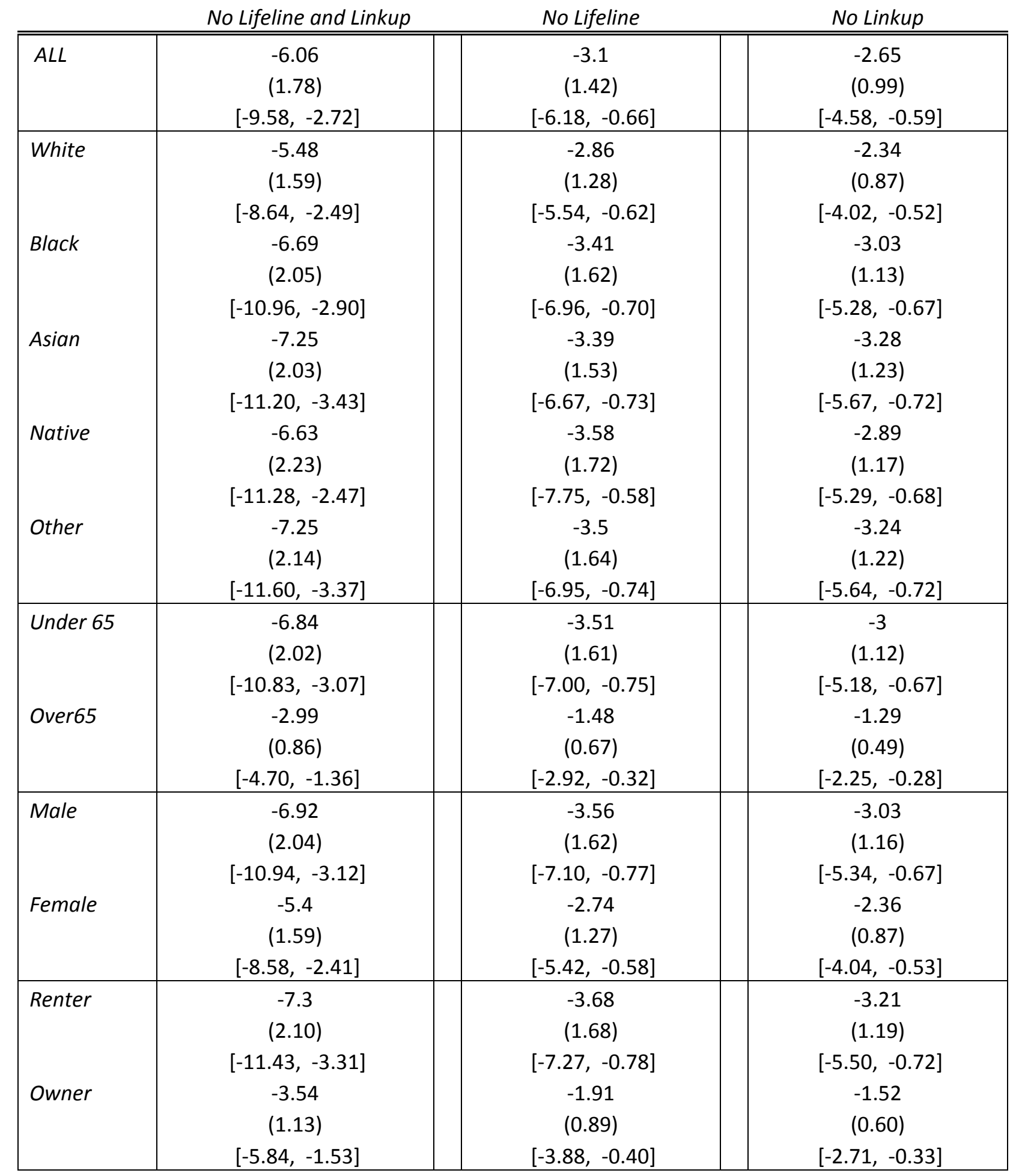

Notes: The table reports estimated changes in penetration from a counterfactual policy change (specified by the column heading), given the lifeline endogenous parameters (third column of Table 3). Standard errors are in parentheses and 95 confidence intervals are in brackets. 
Table 10

Estimated Impact of Subsidy Increases on Penetration

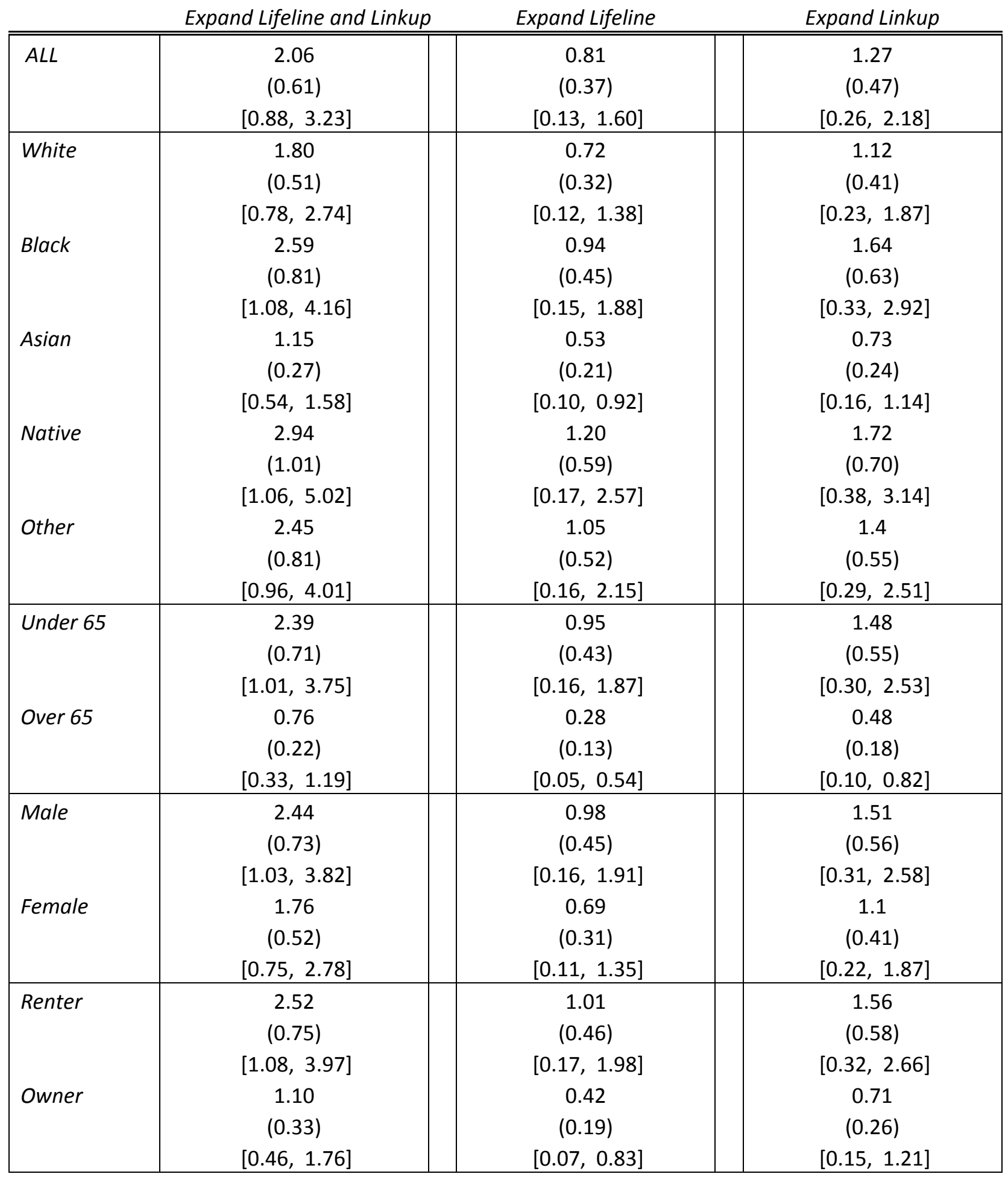

Notes: The table reports estimated changes in penetration from a counterfactual policy change (specified by the column heading), based on the lifeline endogenous parameters (third column of Table 3). Standard errors are in parentheses and 95 confidence intervals are in brackets. 
Figure 1

Lifeline and Linkup Support Payments

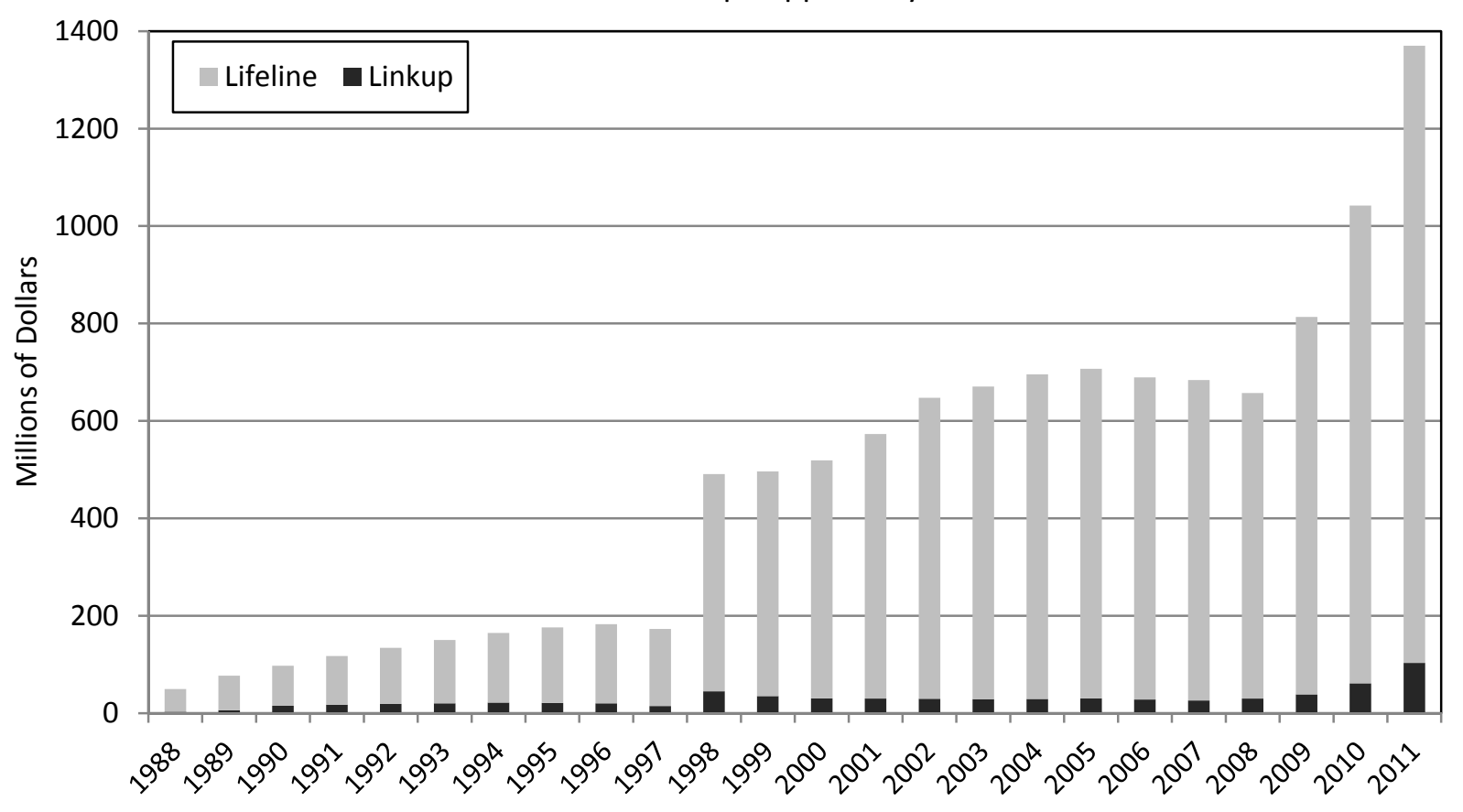

Sources: FCC (2013), BLS. Payments are reported in 2000 dollars, based on the annual CPI-U.

Figure 2
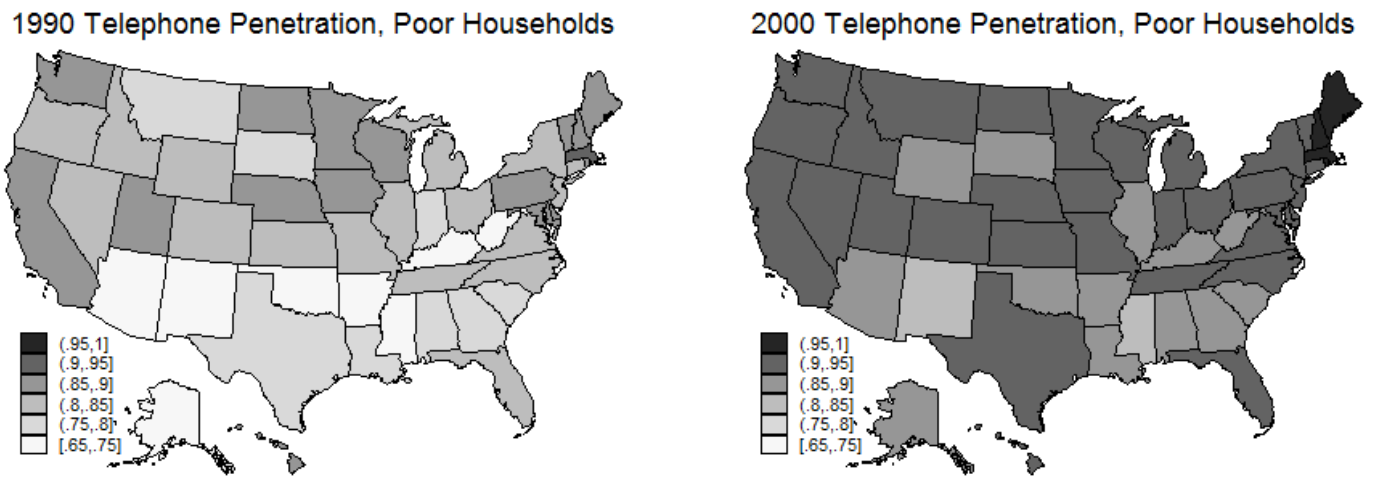

1990 Payments per Poor Household

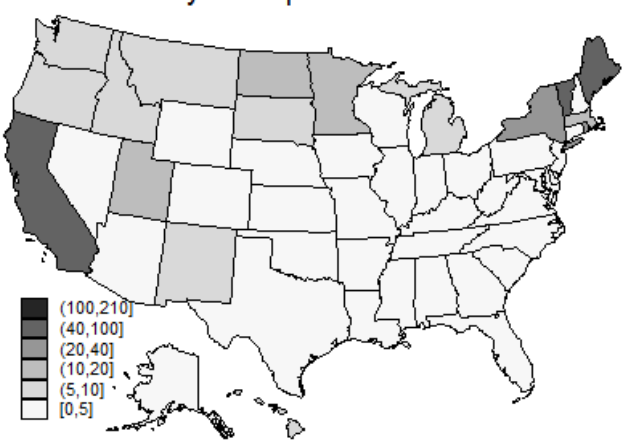

2000 Payments per Poor Household

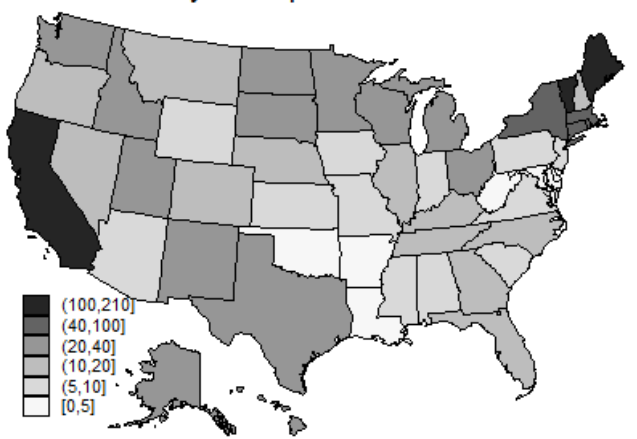

Sources: U.S. Decennial Census (households and penetration), FCC (low-income payments), BLS (CPI-U, to express payments in 2000 dollars) 
Figure 3
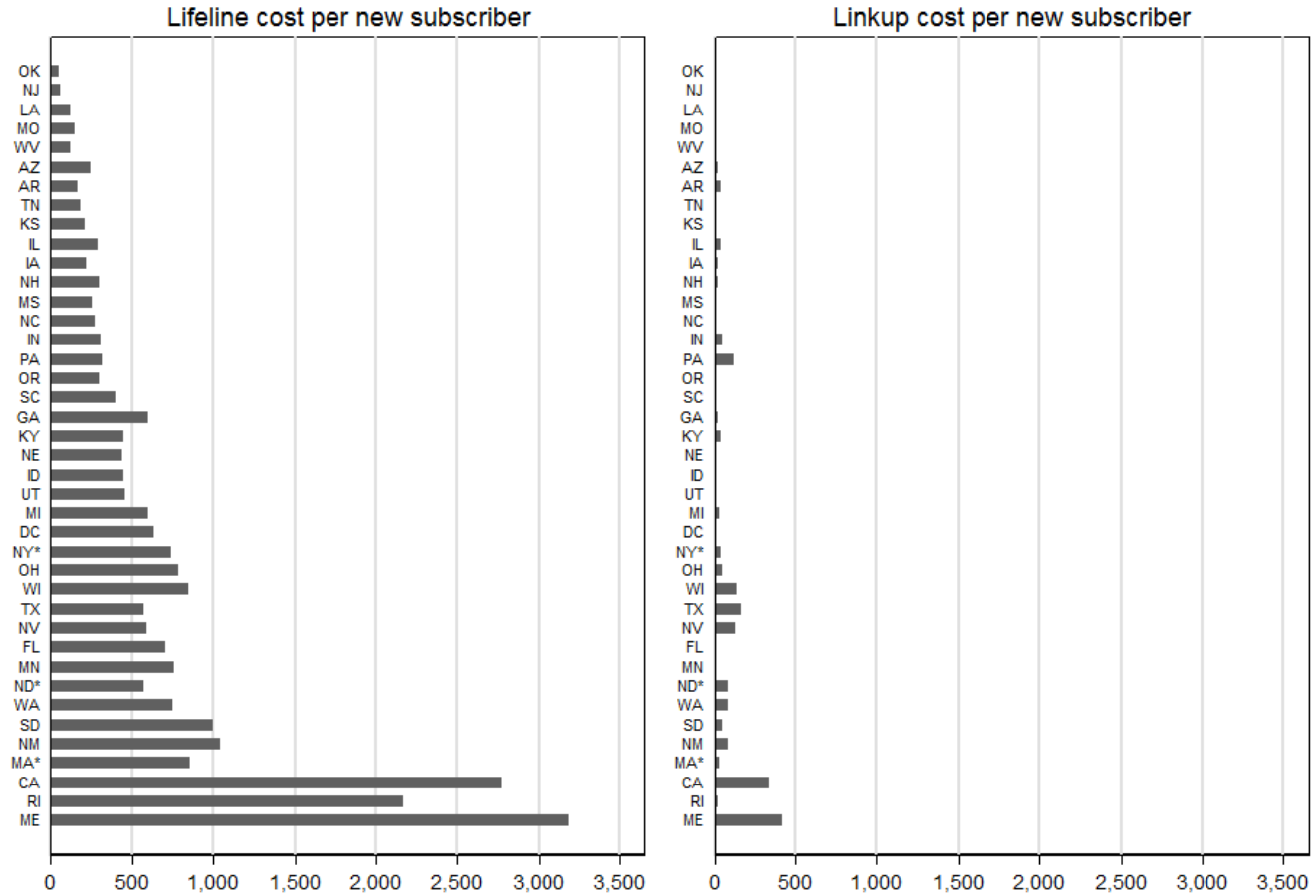

Figure 4
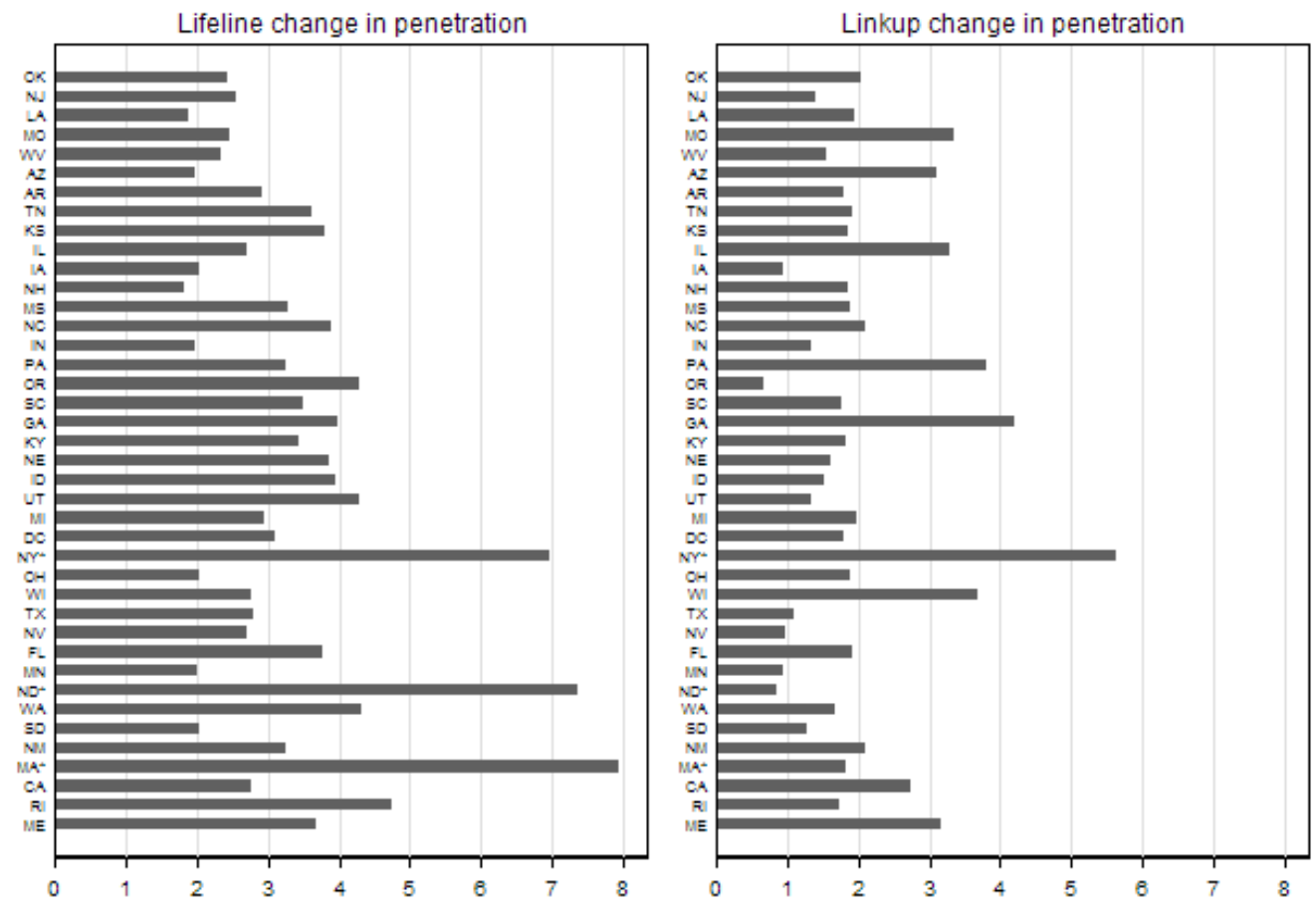

Notes: States are ordered by the total cost per new subscriber for the two programs. The measured Linkup change in penetration is the effect of Linkup from a baseline of no subsidies. The Lifeline change in penetration is the incremental effect of Lifeline subsidies from a baseline of Linkup subsidies. All effects of automatic enrollment policies are attributed to the Lifeline program. The three states with automatic enrollment policies are starred. 